\title{
Beyond Histone and Deacetylase: An Overview of Cytoplasmic Histone Deacetylases and Their Nonhistone Substrates
}

\author{
Ya-Li Yao ${ }^{1}$ and Wen-Ming Yang ${ }^{2}$ \\ ${ }^{1}$ Department of Biotechnology, Asia University, Taichung 41354, Taiwan \\ ${ }^{2}$ Institute of Molecular Biology, National Chung Hsing University, 250 Kuo-Kuang Road, Taichung 40227, Taiwan
}

Correspondence should be addressed to Wen-Ming Yang, yangwm@nchu.edu.tw

Received 20 July 2010; Revised 22 October 2010; Accepted 16 November 2010

Academic Editor: Patrick Matthias

Copyright ( 2011 Y.-L. Yao and W.-M. Yang. This is an open access article distributed under the Creative Commons Attribution License, which permits unrestricted use, distribution, and reproduction in any medium, provided the original work is properly cited.

\begin{abstract}
Acetylation of lysines is a prominent form of modification in mammalian proteins. Deacetylation of proteins is catalyzed by histone deacetylases, traditionally named after their role in histone deacetylation, transcriptional modulation, and epigenetic regulation. Despite the link between histone deacetylases and chromatin structure, some of the histone deacetylases reside in various compartments in the cytoplasm. Here, we review how these cytoplasmic histone deacetylases are regulated, the identification of nonhistone substrates, and the functional implications of their nondeacetylase enzymatic activities.
\end{abstract}

\section{Introduction}

Acetylation is one of the most prominent posttranslational modifications affecting the functions of proteins. The first acetylated protein identified is histone [1]. Twenty-seven years after this discovery, histone acetyltransferases (HATs) and histone deacetylases (HDACs) were identified to be the enzymes responsible for the acetylation and deacetylation of lysines of histone proteins [2, 3]. A year later, lysine modification of nonhistone proteins was confirmed with p53 [4]. Shortly after, many nonhistone proteins were found to be subject to acetylation/deacetylation (reviewed in [5]). Remarkably, a recent genome-wide screening for acetylated proteins shows that lysine acetylation of nonhistone proteins regulates the formation of large protein complexes with key roles in major cellular processes [6]. Therefore, lysine acetylation, both in histones and nonhistone proteins, appears to be a salient mode of regulation in the cell.

In mammals, there are eleven protein deacetylases baring the names HDACs and seven SIRT proteins homologous to yeast Sir2. The subcellular distribution of these HDACs is not limited to the nucleus. Some of them, like HDAC6 and HDAC10, are distributed mainly in the cytoplasm, while SIRT3, 4, and 5 are mitochondrial proteins. A few of them, including HDAC3, SIRT1, and SIRT2, shuttle between the nucleus and the cytoplasm. In this paper, we choose to focus on nonhistone substrates of HDACs, including those in the nucleus and those in the cytoplasm. We will also discuss how these deacetylases are regulated and any non-deacetylase functions they might possess.

\section{HDAC3}

Subcellular localization distinguishes HDAC3 from other class I HDAC subfamily members. HDAC3 shuttles between the nucleus and the cytoplasm by a CRM1-mediated pathway $[7,8]$, suggesting that dynamic localization is a key regulator of the function of HDAC3. In addition to targeting histones during interphase (reviewed in [9]), HDAC3 also targets substrates in the cytoplasm and during mitosis, when the nuclear envelope breaks down and the distinction between nucleus and cytoplasm becomes blurred. Table 1 summarizes the subcellular localization and the functions of nonhistone substrates of HDAC3.

\subsection{Nonhistone, Nuclear Substrates of HDAC3}

2.1.1. MEF2. MEF2 regulates myogenesis and other developmental processes, including apoptosis and cardiac hypertrophy. It has long been shown to interact with class II HDACs 
such as HDAC4 and HDAC5, but how it is deacetylated was unclear. It was later found that MEF2 is sumoylated, not deacetylated, by HDAC4 (discussed in Section 3.4). Interestingly, the classical HDAC that deacetylates MEF2 was identified as HDAC3, and HDAC3 deacetylates MEF2 to repress the MyoD promoter [10].

\subsubsection{Export of SRY and PCAF to the Cytoplasm. HDAC3} affects transcription through a two-fold mechanism: by deacetylating targets in the nucleus and by promoting their nuclear exclusion as a result of deacetylation. Deacetylation of SRY by HDAC3 delocalizes SRY to the cytoplasm [11]. Moreover, HDAC3 promotes translocation of PCAF to the cytoplasm during apoptosis [12]. Coexpression HDAC3 with PCAF not only promotes cytoplasmic retention of PCAF but also that of HDAC3, suggesting a novel interplay between HDAC3 and PCAF. HDAC3-mediated deacetylation might reveal nuclear export signals of substrate proteins and help with their interaction with the CRM1-importin machinery [7].

2.2. Cytoplasmic Substrates of HDAC3. HDAC3-mediated deacetylation of STAT1 prevents its phosphorylation, which is required for nuclear translocation and DNA binding of STAT1 [13]. In addition, HDAC3 activity also regulates STAT3 phosphorylation. HDAC3 deacetylates STAT3 at lysine 685, and an acetylation-resistant mutant of STAT3 loses the dimerization ability [14]. HDAC3 was also found to form complexes with STAT3 and PP2A to mediate dephosphorylation of STAT3 [15]. These findings imply that HDAC3 might be responsible for the cytoplasmic retention of STAT3 as well as STAT1. However, factors or signals that activate HDAC3 remain elusive.

2.3. NF- $\kappa$ B: A Special Substrate of HDAC3 Traversing the Nucleus and the Cytoplasm. HDAC3 deacetylates p65 [16], one of the two components of the most abundant form of the NF- $\kappa \mathrm{B}$ heterodimer. Deacetylation of p65 at lysine 221 promotes binding of $\mathrm{p} 65$ with $\mathrm{I} \kappa \mathrm{B}$ and rapid nuclear exportation. Deacetylation of lysine 310, however, impairs the transcriptional activity of p65 without changing its DNAbinding activity or nuclear export [17]. Acetylation of p65 was also found on lysines 122/123. Deacetylation of these two lysines by HDAC3 maintains p65 in an active state in the nucleus [18]. Interestingly, HDAC3 itself associates with $\mathrm{I} \kappa \mathrm{B}$ in the cytoplasm but translocates into the nucleus under TNF- $\alpha$-induced I $\kappa$ B degradation [19]. These findings suggest that HDAC3 differentially regulates the activity of NF- $\kappa \mathrm{B}$ through deacetylating different lysine residues of p65 and is regulated by $\mathrm{I} \kappa \mathrm{B}$ for cytoplasmic retention.

2.4. Regulation of HDAC3 by Phosphorylation. HDAC3 was found in a protein complex with PP4, and it can be phosphorylated by CK2 [20]. Biochemically, phosphorylation decreases the enzymatic activity of HDAC3 [20]. PP2A also forms a complex with HDAC3 [15]. HDAC3 is phosphorylated at multiple serine/threonine residues during differentiation of endothelial progenitors and interacts with
Akt. This interaction promotes phosphorylation of Akt, increasing its kinase activity [21]. However, despite the apparent phosphorylation of HDAC3, whether phosphorylation changes its subcellular localization, substrate specificity, or deacetylase activity in the cytoplasm remains unclear. More systematic studies are needed to clarify how and why HDAC3 is regulated by phosphorylation in a physiological context.

\subsection{Association of HDAC3 with the Mitotic Chromosome.} HDAC3 was first found to associate with the mitotic chromosome through immunoaffinity purification of the Flag-HDAC3 complex, in which two mitotic chromosomeassociated proteins AKAP95 and HA95 were found [22]. Knockdown of HDAC3 by siRNA blocks histone H3 deacetylation and $\mathrm{H} 3 \mathrm{~S} 10$ phosphorylation, suggesting $\mathrm{H} 3$ modification by this complex. However, the role of AKA95 and HA95, most likely in the recruitment of HDAC3 to the mitotic chromosome, remains unclear. Detailed studies on the role of HDAC3 in mitosis were further extended with add-back strategies using wild-type or deacetylasedead mutants in HDAC3-knockdown cells. HDAC3 and its enzyme activity are required for the formation of functional mitotic spindles and proper kinetochore-microtubule attachment [23]. Fine mapping on chromosomes, using the same strategies, demonstrates that $\mathrm{H} 3 \mathrm{~K} 4$ deacetylation by HDAC3 is required for centromeric functions during mitosis. Loss of HDAC3 impairs centromeric H3T3 phosphorylation, Sgol localization, and H3K4 methylation during mitosis, leading to abnormal sister-chromatid separation and impaired centromeric functions in mitosis [24]. These findings support a novel, nontranscriptional function of HDAC 3 in the cytoplasm during mitosis. It will be interesting to know if AKA95, HA95, and Sgol are also substrates of HDAC3. Further identification of nonhistone targets associated with the mitotic chromosome might reveal more functional links between HDAC3 and mitosis.

2.6. Non Deacetylase Function of HDAC3. A recent report about how phosphorylated orphan nuclear receptor TR2 moves to PML nuclear bodies demonstrated that nuclear relocation of TR2 by HDAC3 is deacetylase independent using TSA and HDAC3 deacetylase-dead mutants [25]. This finding suggests a novel function of HDAC3 as a molecular chaperone and alludes to a previous report that HDAC3 requires proper folding and priming by a chaperone complex called TRiC (TCP-1 ring complex) [26]. Geldanamycin, an inhibitor of chaperone functions, inhibits the formation of the TRiC-HDAC3 complex [26]. Interestingly, a recent report showed that TRiC complexes are acetylated [6]. It remains to be uncovered if the histone deacetylase enzyme activity of HDAC3 affects the chaperone function of TRiC and if HDAC3 has innate chaperone activity.

\section{HDAC4, 5, 7, 9}

HDAC4, 5, 7, and 9 are classified into the class IIa subfamily of HDACs due to similarities in primary structure. Indeed, 
TABLE 1: Subcellular localization and functions of nonhistone substrates of HDAC3.

\begin{tabular}{|c|c|c|c|}
\hline Substrates & Localization of substrates & Functions & Comments \\
\hline MEF2 & Nucleus & Repression of MyoD promoter & $\begin{array}{l}\text { HDAC3 is the only Class I } \\
\text { HDAC that regulates MEF2 } \\
\text { activity }\end{array}$ \\
\hline SRY & Nucleus & Nuclear export & $\begin{array}{l}\text { Deacetylation leads to } \\
\text { cytoplasmic delocalization } \\
\text { Cytoplasmic translocation } \\
\text { promotes apoptosis }\end{array}$ \\
\hline PCAF & Nucleus & Cytoplasmic retention & $\begin{array}{l}\text { Functional interplay between } \\
\text { PCAF and HDAC3 }\end{array}$ \\
\hline STAT1 & Cytoplasm & $\begin{array}{l}\text { Prevention of STAT1 } \\
\text { phosphorylation }\end{array}$ & \\
\hline STAT3 & Cytoplasm & Prevention of dimerization & \\
\hline $\mathrm{NF}-\kappa \mathrm{B}$ & Cytoplasm or nucleus & $\begin{array}{l}\text { Cytoplasmic retention or } \\
\text { activation of p } 65 \text { in the nucleus }\end{array}$ & $\begin{array}{l}\text { Functions are dependent on the } \\
\text { acetylation lysines }\end{array}$ \\
\hline
\end{tabular}

they share similar functions in deacetylating histones in the nucleus and in phosphorylation-regulated subcellular localization (reviewed in $[27,28]$ ). Recent progress on HDAC4 and 7 provides us with valuable information on new substrates, mode of regulation, and novel enzymatic functions of these HDACs. Table 2 summarizes the subcellular localization and the functions of nonhistone substrates of HDAC4 and HDAC7.

3.1. Nonhistone, Nuclear Substrates of HDAC4, and HDAC7. The first reported nonhistone protein substrates of HDAC4 are p53 and Runx2. HDAC4 deacetylates lysines at the C-terminus of $\mathrm{p} 53$, resulting in an increase in the transcriptional repression activity of p53 under DNA damage [29]. Acetylation of Runx2 was found during BMP-2stimulated osteoblast differentiation and bone formation. HDAC4 mediates deacetylation of Runx 2 and promotes Smurf-mediated degradation of Runx2 [30].

It is reported that HDAC7 shuttles into the nucleus under hypoxia and functions as a co-repressor for HIF1 $\alpha$ [31]. Although HDAC7 interacts with HIF1 $\alpha$ and increases the transcriptional activity of $\mathrm{HIF} 1 \alpha$, whether HDAC7 deacetylates HIF $1 \alpha$ remains to be determined.

3.2. Cytoplasmic Substrates of HDAC4. Recently three proteins were found to be potential targets for deacetylation by HDAC4. The Z-disc-associated protein, MLP, can be acetylated by PCAF and deacetylated by HDAC4 in the cytoplasm [32], which is important in the regulation of muscle contraction. HIF $1 \alpha$ interacts with HDAC4 and the cytoplasmic localization of HDAC4 is required for the activity of HIF $1 \alpha$ [33]. As HIF $1 \alpha$ is destabilized by acetylation [34], HDAC4 might help with deacetylation of HIF $1 \alpha$ in the cytoplasm and maintenance of neuronal survival. Moreover, DNAJB8, which is a cytoplasmic chaperone important for suppressing cytotoxic protein aggregation, interacts with HDAC4. Inhibition of HDAC4 reduces the function of DNAJB8 [35]. More cytoplasmic substrates might be found for this subfamily of HDACs in the future.
3.3. Regulation of Nucleocytoplasmic Shuttling of HDAC4 and HDAC7. Nucleocytoplasmic shuttling of HDAC4 is controlled by phosphorylation and dephosphorylation (reviewed in $[28,36]$ ). Phosphorylated HDAC4 binds to 143-3 and stays in the cytoplasm. This cytoplasmic retention might be due to preferential binding of phosphorylated HDAC4 with 14-3-3 in the cytoplasm, resulting in a decrease in nuclear import [37]. Nuclear import of HDAC4 can be attained by dephosphorylation of serine 298 by PP2A, possibly changing the conformation to expose the nuclear localization signal (NLS) [38]. HDAC4 can also be imported into the nucleus through interacting with $\mathrm{MEF} 2 \mathrm{C}$ by using MEF2C's NLS $[38,39]$. A recent paper found that HDAC4interacting protein DNAJB5 is required for its nuclear retention as loss of this interaction relocates HDAC4 to the cytoplasm [40].

In addition to phosphorylation, oxidation also regulates nucleo-cytoplasmic shuttling of HDAC4. Oxidation of HDAC4 at cysteines 667/669 results in the formation of intramolecular disulfide bonds in response to cardiac hypertrophy [40]. In this report, overexpression of a newly identified HDAC4-interacting protein, Trx1 (Thioredoxin 1), suppresses nuclear export of HDAC4 in response to reactive oxygen species (ROS) induced by phenylephrine [40]. It seems that Trx1 regulates the localization of HDAC4 independently of phosphorylation, suggesting multiple ways to regulate nuclear retention of HDAC4.

Finally, proteolysis might control nuclear import of HDAC4 [41, 42]. HDAC4 is cleaved at aspartate 289 by caspase processing, leaving behind the C-terminus of HDAC4 in the cytoplasm [42]. The N-terminal portion of HDAC4 possesses an NLS and accumulates in the nucleus. This fragment also represses the transcriptional activity of MEF2C and increases apoptosis $[41,42]$. Figure 1 summarizes how nucleo-cytoplasmic shuttling of HDAC4 is regulated.

HDAC7 shuttles into the nucleus under hypoxia through an unknown mechanism [43]. It also specifically localizes to PML NBs through interacting with PML [44, 45]. Ectopic expression of PML relieves the repressive effect of HDAC7 on 


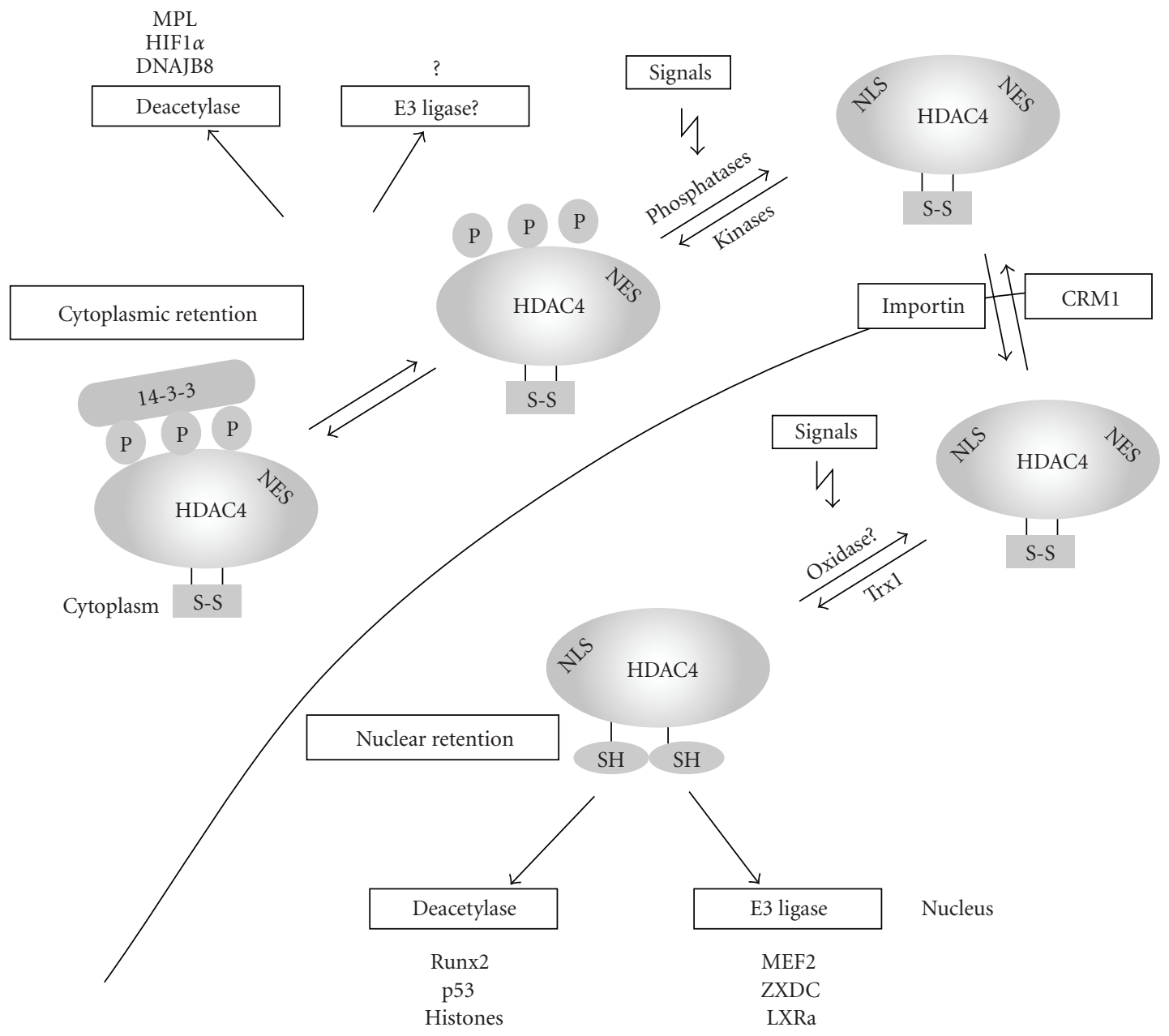

FIGURE 1: A model on the regulation of nucleo-cytoplasmic shuttling and the functions of HDAC4. HDAC4 dynamically shuttles between nucleus and cytoplasm, depending on its phosphorylation status. Phosphorylated HDAC4 binds to 14-3-3 and remains in the cytoplasm. The cytoplasmic form of HDAC4 might possess protein deacetylase activity. Whether cytoplasmic HDAC4 possesses SUMO E3 ligase activity remains unclear. Dephosphorylated HDAC4 is imported into the nucleus, where reduction of HDAC4 by Trx1 favors nuclear retention. Oxidases that catalyze the reverse reaction remain to be identified. Nuclear HDAC4 possesses deacetylase as well as SUMO E3 ligase activities on substrates indicated in the figure.

TABLE 2: Subcellular localization and functions of nonhistone substrates of HDAC4 and HDAC7.

\begin{tabular}{lcclc}
\hline Histone deacetylases & Substrates & Localization of substrates & Functions & Comments \\
\hline HDAC4 & p53 & Nucleus & $\begin{array}{l}\text { Increases repressional activity of } \\
\text { p53 }\end{array}$ & $\begin{array}{l}\text { Under DNA damage } \\
\text { conditions }\end{array}$ \\
\hline Runx2 & Nucleus & $\begin{array}{l}\text { Promotes Smurf-mediated } \\
\text { degradation of Runx2 }\end{array}$ \\
\hline MLP & Cytoplasm & $\begin{array}{l}\text { Regulation of muscle contraction } \\
\text { in cardiac mechanical stretch }\end{array}$ \\
\hline DIF1 $\alpha$ & Cytoplasm & $\begin{array}{l}\text { Cytoplasmic retention to } \\
\text { maintain neuronal survival }\end{array}$ \\
\hline HDAC7 & Cytoplasm & $\begin{array}{l}\text { Suppression of cytotoxic protein } \\
\text { aggregation }\end{array}$ \\
\hline
\end{tabular}


androgen receptor-mediated transcription by sequestering HDAC7 into PML NBs $[44,45]$.

3.4. Sumoylation: A Non-deacetylase Function of HDAC4 and HDAC7. HDAC4 was found to be sumoylated at lysine 559 [46]. When this lysine is mutated to arginine, HDAC4 loses its transcriptional repression and histone deacetylase activity [46]. Interestingly, HDAC4 is also a SUMO E3 ligase in vivo and in vitro, targeting MEF2 at lysines 439 and 424 [47, 48]. Sumoylation of MEF2 by HDAC4 potentiates the transcriptional repression activity of MEF2 specifically for muscle differentiation genes [48]. As MEF2 lysine 424 is acetylated by CBP, these findings suggest that the transcriptional activity of MEF2 is regulated by a balance between acetylation and sumoylation, and sumoylation by HDAC4 may prevent lysine acetylation. Recently, additional sumoylation substrates have been attributed to HDAC4. Sumoylation of a transcription factor called ZXDC by HDAC4 enhances its transcriptional activity [49]. LXR is sumoylated with SUMO2/3 by HDAC4, which turns LXR into a transcriptional co-repressor regulating programs of gene expression that control immunity and homeostasis [50]. $\operatorname{LXR} \alpha$, but not $\operatorname{LXR} \beta$, specifically associates with the STAT1/HDAC4 complex, whereas HDAC4 promotes sumoylation of LXR $\alpha$. Furthermore, sumoylation of LXR $\alpha$ is required for the suppression of STAT1-dependent inflammatory responses by LXRs in brain astrocytes stimulated with IFN- $\gamma$ [51].

HDAC7 was reported to facilitate transcriptional repression in a deacetylase-independent manner [52], which might be a result of sumoylation of HDAC7-interacting proteins. HDAC7 associates with PML, promoting sumoylation of PML as well as the formation of PML NBs [53]. It is possible that the putative E3 enzyme activity of HDAC7 is important for the regulation of androgen receptor-mediated transcription (compare Section 3.3).

\section{HDAC6 and 10}

HDAC6 is a cytoplasmic, class IIb HDAC. Most of the studies focus on its substrate tubulin and how (de)acetylation of tubulin affects lymphocyte chemotaxis, cellular adhesions, aggresome formation, EGFR signaling, HIV infection, stress granules in stress response, and growth factor-induced actin remodeling and endocytosis (reviewed in [54-58]). Here, we focus on recent identification of novel HDAC6 substrates, regulation of HDAC6 deacetylase activity through proteinprotein interactions (summarized in Figure 2 and Table 3), and the biological function of a close relative of HDAC6, HDAC10.

\subsection{Cytoplasmic Substrates of HDAC6}

4.1.1. Hsp90. Hsp90 was the second HDAC6 substrate identified in the cytoplasm after tubulin. Although Hsp90 can be acetylated at different lysines, HDAC6 specifically deacetylates lysine 294 of Hsp90 [64]. Deacetylation of this lysine decreases the chaperone function of Hsp90, specifically Hsp90's interaction with cochaperone p23 and client protein glucocorticoid receptor (GR) ([65]; reviewed in [54]).
Deacetylation of Hsp90 by HDAC6 results in retention of p23 and GR in the cytoplasm, failure of GR maturation, and decreased transcription of target genes. This model is further examined in aryl hydrocarbon receptor (AhR) signaling. Inhibition of HDAC6 blocks the formation of the chaperone complex containing Hsp90, AhR, p23, and XAP-2 as well as the activation of downstream target genes [66].

4.1.2. Cortactin. HDAC6 deacetylates cortactin, an F-actinbinding protein. Deacetylation of cortactin increases its interaction with F-actin [67]. A mutation of cortactin that mimics acetylation prevents its localization to membrane ruffles and inhibits cell motility. HDAC6 knockdown causes the same effect [67]. Based on these findings, Lee and his colleagues found that deacetylation of cortactin by HDAC6 is important for autophagy ([68]; reviewed in [69]).

4.1.3. $\beta$-Catenin. $\beta$-catenin is found to be acetylated at lysine 49 [70], which is frequently mutated in anaplastic thyroid cancer. Acetylation of lysine 49 blocks phosphorylation of serine 45 of $\beta$-catenin [70], which promotes its degradation $[71,72]$. Therefore, HDAC6 inactivation inhibits EGF-induced nuclear translocation $\beta$-catenin, resulting in inhibition of cellular growth [70]. This finding suggests a new role of HDAC6 in the regulation of specific signal transduction pathways.

4.1.4. Peroxiredoxins. Peroxiredoxin (Prx) I and Prx II are antioxidants that reduce $\mathrm{H}_{2} \mathrm{O}_{2}$, a process important in the modulation of intracellular redox status. Deacetylation of Prx I and Prx II by HDAC6 leads to apoptosis [73], suggesting that HDAC6 regulates stress response by altering redox homeostasis.

4.2. Regulation of HDAC6 by Protein-Protein Interaction. Unlike class IIa HDAC members, HDAC6 has not been shown to be regulated through nucleo-cytoplasmic shuttling. Interestingly, several recent reports describe that HDAC6 enzymatic activity is negatively regulated by protein-protein interaction partners (Figure 2 and Table 3), [59-63]. For example, interaction with IIp45 renders HDAC6 unstable [61], while EGFR signaling results in HDAC6 phosphorylation at tyrosine 570, reducing its deacetylase activity [63]. Studies from these newly identified HDAC6-interacting proteins suggest that, in addition to direct chemical inhibition, HDAC6 can be subject to regulation by extracellular and intracellular stimuli.

4.3. HDAC10: An Enigmatic Relative of HDAC6. While HDAC6 plays multiple roles in the cytoplasm, very little is known about another cytoplasmic deacetylase, HDAC10, which is closest to HDAC6 (reviewed in [55]). Recently, HDAC10 is shown to target nonhistone substrates both in the nucleus and the cytoplasm [74]. Using immunoaffinity purification, Hsp70 was identified as the most abundant protein associated with HDAC10 and HDAC10 only interacts with a deacetylated form of Hsp70, suggesting that HDAC10 might contribute to the deacetylation status of Hsp70 [74]. 


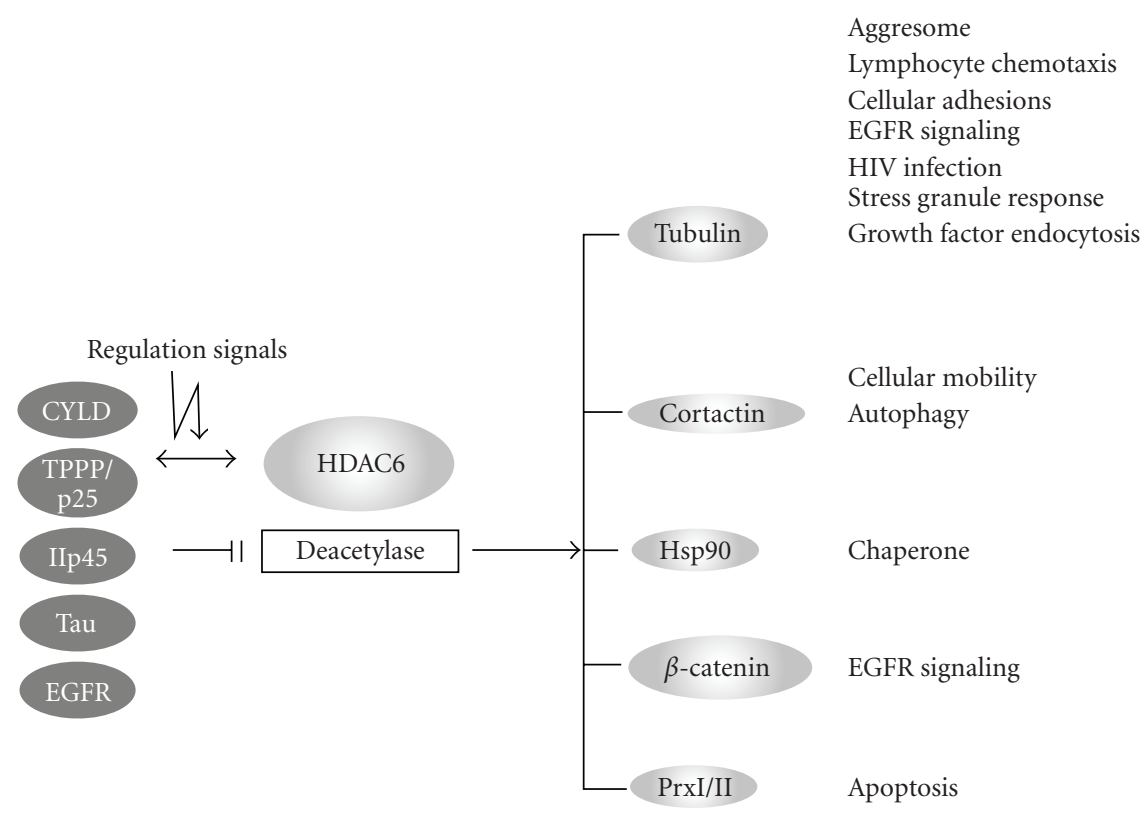

FIGURE 2: Regulation and functional ramifications of the HDAC6 deacetylase activity. Interaction with protein partners reduces protein deacetylase activity of HDAC6, which is important for the deacetylation of substrate proteins and cellular effects as indicated.

TABLE 3: Proteins interacting with and inhibiting the deacetylase activity of HDAC6.

\begin{tabular}{llcc}
\hline Interacting proteins & Substrates affected & Functions involved & References \\
\hline TPPP/p25 & Tubulin & Decrease cell mobility & Cell proliferation \\
CYLD & Tubulin & Cell migration & {$[59]$} \\
IIp45 & Tubulin (decreases stability of HDAC6) & Prevent autophagy & {$[60]$} \\
Tau & Tubulin & Decrease endocytosis and & degradation \\
EGFR & Tubulin (decreases deacetylase activity of & [63] \\
\hline
\end{tabular}

Using a specific histone deacetylase inhibitor FK228 to treat K562 cells, acetylation of Hsp70 is increased while that of Hsp90 remains unchanged [75]. Interestingly, acetylated Hsp70 specifically interacts with c-Abl and Bcr-Abl in K562 cells, promoting Bcr-Abl degradation [75]. These results suggest that acetylation of Hsp70, which possibly results from deregulation of HDAC10 rather than HDAC6, might cause incorrect folding of substrate proteins in the cytoplasm and subsequent degradation (Figure 3). Furthermore, HDAC10 might target nonhistone proteins important in transcriptional regulation. HDAC10 interacts with deacetylated forms of Pax3 and KAP1, resulting in derepression of Pax3 target genes during melanogenesis [74]. These lines of evidence suggest that, like HDAC6, HDAC10 has nonhistone targets in both the nucleus and the cytoplasm. Full revelations of the physiologic functions of HDAC10 will come from identification of additional HDAC10 targets.

\section{SIRT1-5}

Sir2 is an $\mathrm{NAD}^{+}$-dependent deacetylase that extends life span in yeast. Mammalian SIRT proteins, or sirtuins, are yeast Sir2 homologs that regulate diverse processes including life span, energy metabolism, stress response, DNA repair, and tumorigenesis. Seven mammalian SIRT proteins have been identified to date. Most reviews focus on SIRT1, the closest relative of yeast Sir2, and SIRT2 (for a very recent review on SIRT1 and 2, see [76]). Mitochondrial sirtuins are usually reviewed separately [77-79]. In this section, we will briefly discuss the functions of SIRT1 and SIRT2 in the cytoplasm as their general (nuclear) functions are extensively reviewed in the literature, summarize the functions of SIRT3, 4, 5 that reside in the mitochondrion, and omit chromatinassociating SIRT6 and nucleolar-residing SIRT7. For a concise overview of the function of all seven sirtuins, readers are referred to recent reviews such as [80-82]. Table 4 summaries the substrates and the functions of these cytoplasmic sirtuins.

5.1. SIRT1. The subcellular localization of SIRT1 is cell type dependent. Studies using cell lines and animals show that in some cells SIRT1 is predominately nuclear while in others it is predominately cytoplasmic $[83,84]$. Two nuclear localization signals and two nuclear export signals have been identified in SIRT1 $[83,84]$. Cytoplasmic localization of SIRT1, mediated 


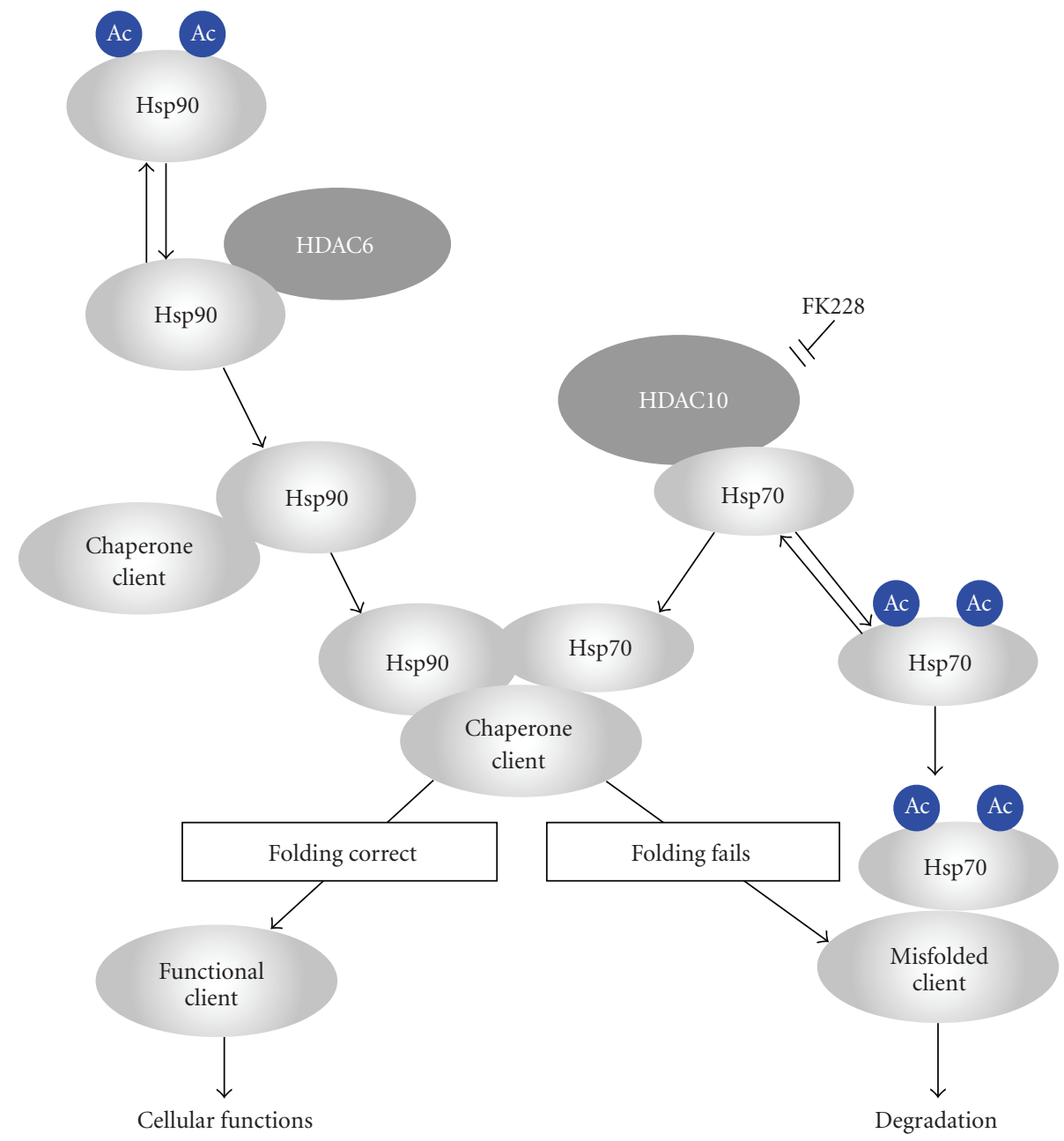

FIgURE 3: A model of how HDAC6/Hsp90 and HDAC10/Hsp70 collaboratively work as protein chaperones. Deacetylation of Hsp90 catalyzed by HDAC6 might prime its chaperone function. Deacetylated Hsp70, catalyzed by HDAC10 or by another deacetylase, joins the Hsp90/chaperone client complexes to help with correct folding of the clients. Acetylation of Hsp70, a likely result of HDAC10 deregulation, might cause incorrect folding of proteins or facilitate the subsequent degradation of misfolded proteins.

by a CRM1-dependent nuclear export pathway, might be regulated by differentiation [83]. However, the cytoplasmic presence of SIRT1 has also been linked to a propensity for apoptosis, as cytoplasmic translocation of nuclear SIRT1 increases apoptosis $[83,84]$.

Questions remain about the physiologic significance of cytoplasmic SIRT1 as well as the detailed mechanism of apoptotic regulation by cytoplasmic translocation of SIRT1. It has been shown, almost a decade ago, that SIRT1 suppresses stress-induced apoptosis by deacetylating p53 $[85,86]$. In studies using mammalian cells and tissues, cytoplasmic SIRT1 promotes apoptosis induced by oxidative stress and nocodazole, a metaphase apoptosis inducer [83, 84]. These results suggest that elucidation of how SIRT1 responds to cellular stress and then translocates to the cytoplasm will be key to full understanding of how SIRT1 regulates apoptosis.

In genetic assays using C. elegans, it appears that SIR-2.1, the worm homolog of SIRT1, also induces apoptosis in a manner that depends on its cytoplasmic translocation from the nucleus [87]. However, this study shows that SIR-2.1 specifically activates the apoptotic program induced by DNA damage in germ cells [87]. It will be interesting to find out whether the differences in the worm study and the studies in mammalian cells are a result of experimental design, or SIRT1-mediated apoptosis indeed has inherent specificity.

5.2. SIRT2. SIRT2 is predominately cytoplasmic [88], with nuclear-cytoplasmic shuttling reported $[89,90]$. The biological function of SIRT2 was first revealed by the identification that SIRT2 is an $\mathrm{NAD}^{+}$-dependent deacetylase specific for $\alpha$ tubulin [88]. A number of nuclear substrates deacetylated by SIRT2 has also been identified, including p53, FOXO1, FOXO3a, histone $\mathrm{H} 4$, histone $\mathrm{H} 3$, and p300 [91-96], whereas the biological significance of these nuclear substrates will be excluded from the discussion here. The deacetylase activity of SIRT2 is modulated by phosphorylation and acetylation, although the exact subcellular localization of these modifications remains unspecified. Phosphorylation of the SIRT2 protein at serine 368, which inhibits SIRT2 
TABLE 4: Cytoplasmic sirtuins, their substrates in the cytoplasm, and their functions.

\begin{tabular}{|c|c|c|c|}
\hline $\begin{array}{l}\text { Mammalian cytoplasmic } \\
\text { sirtuins }\end{array}$ & Substrates & Functions & Comments \\
\hline $\begin{array}{l}\text { SIRT1 (subcellular } \\
\text { localization is cell type } \\
\text { dependent) }\end{array}$ & & $\begin{array}{l}\text { Cytoplasmic localization of } \\
\text { SIRT1 is linked to apoptosis }\end{array}$ & $\begin{array}{l}\text { Whether SIRT1 enhances or decreases } \\
\text { apoptosis and the mechanistic details } \\
\text { remain unclear }\end{array}$ \\
\hline $\begin{array}{l}\text { SIRT2 (shuttles between } \\
\text { nucleus and cytoplasm) }\end{array}$ & $\alpha$-tubulin & $\begin{array}{l}\text { Mitotic exit of normal cell } \\
\text { cycle } \\
\text { Regulation of mitotic } \\
\text { checkpoint under stress } \\
\text { Neuronal motility and } \\
\text { differentiation }\end{array}$ & $\begin{array}{l}\text { Subcellular localization of SIRT2 } \\
\text { modifications that modulate } \\
\text { deacetylase activity of SIRT2, namely, } \\
\text { phosphorylation and acetylation, is } \\
\text { largely unspecified } \\
\text { Mechanism(s) through which SIRT2 } \\
\text { regulates mitotic exit remains unclear }\end{array}$ \\
\hline $\begin{array}{l}\text { SIRT3 } \\
\text { (in mitochondria) }\end{array}$ & $\begin{array}{c}\text { AceCS2 } \\
\text { GDH } \\
\text { ICDH2 } \\
\text { Complex I of electron transport } \\
\text { chain } \\
\text { Ku70 } \\
\text { Nampt } \\
\text { MRPL10 } \\
\end{array}$ & $\begin{array}{l}\text { Regulation of energy } \\
\text { metabolism and apoptosis }\end{array}$ & $\begin{array}{l}\text { GDH activity is not significantly } \\
\text { altered in Sirt3 knockout mice }\end{array}$ \\
\hline $\begin{array}{l}\text { SIRT4 } \\
\text { (in mitochondria) }\end{array}$ & $\begin{array}{c}\text { GDH } \\
\text { (SIRT4 also interacts with ANT2, } \\
\text { SIRT3, and IDE) }\end{array}$ & $\begin{array}{l}\text { Regulation of insulin } \\
\text { secretion }\end{array}$ & $\begin{array}{l}\text { SIRT4 is an ADP ribosylase } \\
\text { No deacetylase activity is reported for } \\
\text { SIRT4 } \\
\text { ADP-ribosylation of ANT2, SIRT3, or } \\
\text { IDE by SIRT4 has not been shown } \\
\text { definitely }\end{array}$ \\
\hline $\begin{array}{l}\text { SIRT5 } \\
\text { (in mitochondria) }\end{array}$ & CPS1 cytochrome $c$ & $\begin{array}{l}\text { Regulation of urea cycle } \\
\text { Promotes apoptosis? }\end{array}$ & $\begin{array}{l}\text { Exact submitochondrial localization of } \\
\text { SIRT5, how calorie restriction alters } \\
\text { CPS1 acetylation through SIRT5, and } \\
\text { what lysines in CPS1 are acetylated } \\
\text { under different nutrient availability } \\
\text { remain controversial }\end{array}$ \\
\hline
\end{tabular}

activity, is mediated by cyclin-dependent kinases Cdk1, Cdk2, and Cdk5 [97, 98]. Dephosphorylation of SIRT2 is attributed to CDC14B [97, 99]. Acetylation of SIRT2 by p300, which is also a substrate of SIRT2, downregulates the activity of SIRT2 [100]. SIRT2 also interacts with HDAC6, HOXA10, 14-3-3 $\beta / \gamma$, and members of the DNAJB chaperone family $[35,88,92,101]$.

Compared with other mammalian sirtuins, SIRT2 expresses abundantly in the brain [98, 102]. Given that SIRT2 deacetylates $\alpha$-tubulin, SIRT2 might be instrumental in the regulation of neuronal processes involving microtubules, such as neurite outgrowth, dynamics of cytoskeletal growth cones, oligodendrocyte arborization, and migration of glioma (reviewed in [103]). SIRT2 has also been implicated in the proliferation of gliomas [104]. Further studies show that SIRT2 regulates mitotic exit from the normal cell cycle as well as mitotic checkpoints under mitotic stress induced by microtubule inhibitors $([99,105,106]$ and reviewed in $[82])$.

SIRT2 has been implicated in the regulation of mitotic exit. It accumulates during G2/M transition, and overexpressed SIRT2 prolongs mitosis [99, 101]. Furthermore, microinjection of O-acetyl-ADP-ribose formed during SIRT2-mediated deacetylation or low amounts of human
SIRT2 blocks starfish oocyte maturation [107]. It is postulated that a decrease in the amount or enzymatic activity of SIRT2 is required for proper mitotic exit. Findings showing how SIRT2 is regulated by cyclin-dependent kinases and $\mathrm{CDC} 14 \mathrm{~B}$, which is important for cytokinesis, seem to support this hypothesis. However, the detailed mechanism of how SIRT2 regulates mitotic exit remains elusive.

Studies from the Oshimura group further found that SIRT2 blocks chromosome condensation in the presence of microtubule poisons such as nocodazole, enabling a mitotic checkpoint $[105,106]$, a phenomenon previously ascribed to the prophase checkpoint protein CHFR [108]. SIRT2 appears to be necessary to rescue cells from prolonged mitotic arrest and to avoid secondary outcomes such as cell death and hyperploidy that usually accompany release from such mitotic arrest [106]. Furthermore, downregulation of SIRT2 using siRNA causes centrosome fragmentation before the activation of the mitotic checkpoint elicited by nocodazole [106]. These results suggest that SIRT2 is crucial in the regulation of mitotic checkpoints and centrosome integrity.

5.3. SIRT3. SIRT3 is a mitochondrial matrix protein that regulates mitochondrial protein acetylation [109-111], and 
its $\mathrm{N}$-terminal mitochondrial targeting sequence needs to be removed for full deacetylase activity $[111,112]$. It has been suggested that SIRT3 might translocate to the nucleus [113115], and the nuclear presence of SIRT3 requires both the mitochondrial targeting signal as well as the putative nuclear localization signal [113]. The physiological significance of the presence of SIRT3 in the nucleus, the mitochondrion, or even the cytoplasm remains controversial (reviewed in [116]). Some studies suggest that it depends on whether the SIRT3 protein is proteolytically processed [115], as both a long form and a short form of the SIRT3 protein have been reported [117-120] and cleavage of SIRT3 affects subcellular location [115].

The substrates of SIRT3 known to date fall into two categories: those involved in energy metabolism and those involved in apoptosis. The former group includes acetylcoenzyme A synthase 2 (AceCS2) [111, 121], glutamate dehydrogenase (GDH) [79], isocitrate dehydrogenase 2 (ICDH2) [79], and Complex I of the electron transport chain [122]. The latter includes Ku70 [115], nicotinamide phosphoribosyltransferase (Nampt) [123], and MRPL10 (mitochondrial ribosomal protein L10) [124].

Deacetylation of AceCS2 at lysine 642 by SIRT3 activates the enzymatic activity of AceCS2 [111, 121], which converts acetate into acetyl-CoA [125]. GDH converts glutamate to $\alpha$-ketoglutarate [126]. In vitro deacetylation of GDH by SIRT3 activates its activity by $10 \%$ [79], and GDH is hyperacetylated in Sirt3 knockout mice [109]. However, GDH activity is not significantly altered in Sirt3 knockout mice [127]. SIRT3 deacetylates and activates the activity of ICDH2 in vitro in a dose-dependent manner [79]. Components of the electron transport chain Complex I show increased acetylation levels and decreased activity in Sirt $3^{-/-}$ cells [122]. SIRT3 also physically interacts with the NDUFA9 subunit of Complex I [122].

In cardiomyocytes, SIRT3 deacetylates Ku70 and promotes association between Ku70 and Bax, thereby preventing Bax-mediated apoptosis [115]. Studies using siRNA show that SIRT3 (and SIRT4) is required for Nampt-mediated protection against methylmethane sulfonate-induced cell death [123]. Nampt catalyzes the rate-limiting step in $\mathrm{NAD}^{+}$ biosynthesis from NAM $[128,129]$ and is upregulated by fasting or cell stress [123]. Upregulation (an increase in protein amount) of Nampt by nutrient deprivation might be a result of SIRT3-mediated deacetylation and activation of mitochondrial ribosomal protein MRPL10, which enhances mitochondrial protein synthesis [124]. Interestingly, angiotensin II (Ang II) downregulates the mRNA level of Sirt3, and this downregulation is inhibited by application of an antagonist to Ang II type 1 receptor [130]. These results suggest that SIRT3 promotes longevity and cellular response to different forms of stress through a multiple of mechanisms. However, as SIRT3 is also reported as a proapoptotic factor [131], the role of SIRT3 in apoptosis requires additional evidence to clarify.

5.4. SIRT4. SIRT4 resides in the mitochondrial matrix [132-134]. SIRT4 has not been shown to possess protein deacetylase activity. Instead, it ADP ribosylates glutamate dehydrogenase (GDH) [133]. In mitochondria, GDH catalyzes the conversion of glutamate to $\alpha$-ketoglutarate, which subsequently enters the tricarboxylic acid cycle [126]. ADP ribosylation by SIRT4 inhibits the enzymatic activity of GDH and hinders the metabolism of glutamine and glutamate to generate ATP [133]. As a result, SIRT4 represses insulin secretion of pancreatic $\beta$ cells in response to glucose and amino acids.

Further evidence that SIRT4 regulates insulin secretion comes from the finding that SIRT4 associates with adenine nucleotide translocator 2 (ANT2) [132]. Metabolites from glycolysis and tricarboxylic acid cycle fuel the production of ATP through oxidative phosphorylation, which leads to an increase in the level of ATP in the mitochondrial matrix. ATP/ADP translocators such as ANT2 facilitate exchange of mitochondrial ATP for cytosolic ADP, causing an increase of the cytosolic ATP/ADP ratio. In response, ATPsensitive $\mathrm{K}^{+}$channels close, which leads to plasma membrane depolarization and opening of the voltage-dependent $\mathrm{Ca}^{2+}$ channels. The resulting flux of intracellular $\mathrm{Ca}^{2+}$ prompts insulin exocytosis (reviewed in [135]). Therefore, findings that SIRT4 ADP ribosylates GDH and interacts with ANT2 strongly support a role of SIRT4 in the regulation of insulin secretion. An inverse relationship between GDH activity and ADP-ribosylation is also observed during calorie restriction (CR) in that hepatic GDH activity is elevated while the level of ADP-ribosylation of GDH is decreased [133]. Interestingly, CR induces amino acid-stimulated insulin secretion in pancreatic islets $[133,136]$. These phenomena allude to previous findings that, during $\mathrm{CR}$, amino acids serve as carbon sources $[136,137]$. However, they do not explain the need to upregulate the activity of GDH and the secretion of insulin during $\mathrm{CR}$.

The studies surrounding GDH and insulin secretion inevitably raise the question of how the ADP-ribosylase activity of SIRT4 is regulated. Unfortunately, there is no clear answer to that question. However, SIRT3, another mitochondrial sirtuin that interacts with Complex I of the electron transport chain [122] and shows weak deacetylase activity toward GDH [79], interacts with SIRT4 [132]. SIRT4 also interacts with insulin-degrading enzyme (IDE), although it has not been shown clearly whether IDE can be ADP-ribosylated by SIRT4 [132]. It is tempting to speculate that the activity of SIRT4 is regulated by another sirtuin, perhaps by $\mathrm{NAD}^{+}$-dependent deacetylation or by a certain kind of insulin-sensing mechanism. Further experimental support is needed to answer these questions.

5.5. SIRT5. The N-terminal 36 amino acids of SIRT5 are removed after SIRT5 is imported into the mitochondrial matrix $[127,138]$. However, debates remain surrounding the exact location of SIRT5 in the mitochondrion. Endogenous murine SIRT5 shows exclusive matrix localization [127]. However, overexpressed SIRT5 is located in the mitochondrial intermembrane space (IMS) in COS7 cells [113]. To add to the confusion, in vitro import assay using isolated yeast mitochondria shows that human SIRT5 is imported into both the IMS and the matrix [79]. There is also a report showing that SIRT5 exists in both the nucleus and 
the cytoplasm [139]. To fully understand the physiological significance as well as regulation of SIRT5, the exact cellular location of this sirtuin needs to be determined.

The in vivo substrate of SIRT5 has recently been identified as carbamoyl phosphate synthase 1 (CPS1) in an immunocapture screen for SIRT5-interacting partners [127]. CPS1 is the committed enzyme of the urea cycle, which is important for the removal of excess ammonia $[140,141]$. Excess ammonia is generated during fasting or as a result of high-protein diet [141-144]. Activation of CPS1 by SIRT5 is, therefore, crucial for the conversion of ammonia into carbamoyl phosphate, and ultimately, urea. $\mathrm{NAD}^{+}$-dependent deacetylation of CPS1 by SIRT5 activates the enzymatic activity of CPS1 in vitro, and CPS1 activity is decreased in Sirt5 knockout mice [127]. Nutrient deprivation induces CPS1 activity in normal primary hepatocytes [127]. More importantly, during starvation, Sirt5 knockout mice show higher levels of blood ammonia, lower CPS1 activity, and higher levels of CPS1 acetylation compared with wildtype animals [127]. However, in Sirt $5^{-/-}$cells, CPS1 activity is less sensitive to nutrient deprivation treatment [127].

It appears that CR for 6 months brings about a decreased level of CPS1 acetylation in normal mice, lower than that observed for animals fed ad libitum but higher than in fasted animals [127]. However, the acetylation level of CPS1 has also been reported to be increased by CR [145]. Potential controversy exists regarding the level and particular lysines acetylated in CPS1 in response to varied nutrient availability (discussed in [78]). Along the lines of energy metabolism, it has been shown that the mitochondrial level of $\mathrm{NAD}^{+}$ increases about twofold while that of NADH remains constant during fasting, and SIRT5 activity is stimulated by $\mathrm{NAD}^{+}$with a $K_{\mathrm{m}}$ of $50-100 \mu \mathrm{M}$ in vitro [127]. Moreover, ethanol causes a decrease in both $\mathrm{NAD}^{+}$level [146] and the activity of SIRT5 [147]. These findings raise the possibility that SIRT5 is regulated by the level of $\mathrm{NAD}^{+}$. However, as $\mathrm{NAD}^{+}$affects the activity of many sirtuins, more biochemical analysis is needed to discriminate the differences between sirtuins in their response to $\mathrm{NAD}^{+}$levels.

In addition to CPS1, cytochrome $c$ has been reported to be deacetylated by SIRT5 in an ELISA-based system and colocalizes with SIRT5 in the IMS [79]. It is possible that SIRT5-mediated deacetylation contributes to the regulation of the proapoptogenic activity of cytochrome $c$. Furthermore, overexpressed and mitochondrially localized SIRT5 promotes apoptosis in cerebellar granule neurons and in HT-22 neuroblastoma cells [139]. The role of SIRT5 in apoptosis no doubt depends on its exact subcellular location, and the causal relationship between SIRT5 and apoptosis remains to be clarified.

\section{Concluding Remarks}

Acetylation is a rather common form of post-translational modification [6]. However, when, how, and which deacetylases regulate the acetylation status of proteins remain largely unknown. Recent studies about HDAC3 and NF- $\kappa \mathrm{B}$ also remind us that deacetylation of different lysines on the same substrate protein can have divergent consequences.
Therefore, the field of protein acetylation is far from mature. Future advances will likely come from understanding of how the activity of deacetylases is regulated as well as identification of novel, non-deacetylase activities. We now know that multiple inputs, coming from interactions with cytoplasmic proteins, are integrated into HDAC6 to regulate its deacetylase activity. Moreover, HDAC4 and HDAC7 participate in protein sumoylation, while HDAC3 might function as a protein chaperone. Similar discoveries will further enlighten us on this fascinating group of proteins and clarify some of the controversies surrounding the mechanistic details of mammalian sirtuins.

\section{Acknowledgments}

The authors apologize for not being able to cite all pertinent references due to space limitation. This work is supported by Grants from the National Science Council of Taiwan (NSC 98-2311-B-468-001-MY3 to Y.-L. Yao and NSC 99-2311-B005-005-MY3 to W.-M. Yang).

\section{References}

[1] A. Inoue and D. Fujimoto, "Enzymatic deacetylation of histone," Biochemical and Biophysical Research Communications, vol. 36, no. 1, pp. 146-150, 1969.

[2] J. E. Brownell, J. Zhou, T. Ranalli et al., “Tetrahymena histone acetyltransferase A: a homolog to yeast Gcn5p linking histone acetylation to gene activation," Cell, vol. 84 , no. 6, pp. 843851, 1996.

[3] J. Taunton, C. A. Hassig, and S. L. Schreiber, "A mammalian histone deacetylase related to the yeast transcriptional regulator Rpd3p," Science, vol. 272, no. 5260, pp. 408-411, 1996.

[4] W. Gu and R. G. Roeder, "Activation of p53 sequence-specific DNA binding by acetylation of the p53 C-terminal domain," Cell, vol. 90, no. 4, pp. 595-606, 1997.

[5] M. A. Glozak, N. Sengupta, X. Zhang, and E. Seto, "Acetylation and deacetylation of non-histone proteins," Gene, vol. 363, no. 1-2, pp. 15-23, 2005.

[6] C. Choudhary, C. Kumar, F. Gnad et al., "Lysine acetylation targets protein complexes and co-regulates major cellular functions," Science, vol. 325, no. 5942, pp. 834-840, 2009.

[7] W. M. Yang, S. C. Tsai, YU. D. Wen, G. Fejé, and E. Seto, "Functional domains of histone deacetylase-3," Journal of Biological Chemistry, vol. 277, no. 11, pp. 9447-9454, 2002.

[8] W. M. Yang, Y. L. Yao, J. M. Sun, J. R. Davie, and E. Seto, "Isolation and characterization of cDNAs corresponding to an additional member of the human histone deacetylase gene family," Journal of Biological Chemistry, vol. 272, no. 44, pp. 28001-28007, 1997.

[9] P. Karagianni and J. Wong, "HDAC3: taking the SMRT-NCoRrect road to repression," Oncogene, vol. 26, no. 37, pp. 5439-5449, 2007.

[10] S. Grégoire, L. Xiao, J. Nie et al., "Histone deacetylase 3 interacts with and deacetylates myocyte enhancer factor 2," Molecular and Cellular Biology, vol. 27, no. 4, pp. 1280-1295, 2007.

[11] L. Thevenet, C. Méjean, B. Moniot et al., "Regulation of human SRY subcellular distribution by its acetylation/deacetylation," EMBO Journal, vol. 23, no. 16, pp. 33363345, 2004. 
[12] N. Blanco-García, E. Asensio-Juan, X. de la Cruz, and M. A. Martínez-Balbás, "Autoacetylation regulates P/CAF nuclear localization," Journal of Biological Chemistry, vol. 284, no. 3, pp. 1343-1352, 2009.

[13] O. H. Krämer, S. K. Knauer, G. Greiner et al., "A phosphorylation-acetylation switch regulates STAT1 signaling," Genes and Development, vol. 23, no. 2, pp. 223-235, 2009.

[14] Z. L. Yuan, Y. J. Guan, D. Chatterjee, and Y. E. Chin, "Stat3 dimerization regulated by reversible acetylation of a single lysine residue," Science, vol. 307, no. 5707, pp. 269-273, 2005.

[15] S. Togi, S. Kamitani, S. Kawakami et al., "HDAC3 influences phosphorylation of STAT3 at serine 727 by interacting with PP2A," Biochemical and Biophysical Research Communications, vol. 379, no. 2, pp. 616-620, 2009.

[16] L. F. Chen, W. Fischle, E. Verdin, and W. C. Greene, "Duration of nuclear NF- $\kappa \mathrm{B}$ action regulated by reversible acetylation," Science, vol. 293, no. 5535, pp. 1653-1657, 2001.

[17] W. C. Greene and L. F. Chen, "Regulation of NF- $\kappa$ B action by reversible acetylation," Novartis Foundation Symposium, vol. 259, pp. 208-225, 2004.

[18] R. Kiernan, V. Brès, R. W. M. Ng et al., "Post-activation turn-off of NF- $\kappa \mathrm{B}$-dependent transcription is regulated by acetylation of p65," Journal of Biological Chemistry, vol. 278, no. 4, pp. 2758-2766, 2003.

[19] Z. Gao, Q. He, B. Peng, P. J. Chiao, and J. Ye, "Regulation of nuclear translocation of HDAC3 by $\mathrm{I} \kappa \mathrm{B} \alpha$ is required for tumor necrosis factor inhibition of peroxisome proliferatoractivated receptor $\gamma$ function," Journal of Biological Chemistry, vol. 281, no. 7, pp. 4540-4547, 2006.

[20] X. Zhang, Y. Ozawa, H. Lee et al., "Histone deacetylase 3 (HDAC3) activity is regulated by interaction with protein serine/threonine phosphatase 4," Genes and Development, vol. 19 , no. 7, pp. 827-839, 2005.

[21] A. Zampetaki, L. Zeng, A. Margariti et al., "Histone deacetylase 3 is critical in endothelial survival and atherosclerosis development in response to disturbed flow," Circulation, vol. 121, no. 1, pp. 132-142, 2010.

[22] Y. Li, G. D. Kao, B. A. Garcia et al., "A novel histone deacetylase pathway regulates mitosis by modulating Aurora B kinase activity," Genes and Development, vol. 20, no. 18, pp. 2566-2579, 2006.

[23] S. Ishii, Y. Kurasawa, J. Wong, and L. Y. Yu-Lee, "Histone deacetylase 3 localizes to the mitotic spindle and is required for kinetochore-microtubule attachment," Proceedings of the National Academy of Sciences of the United States of America, vol. 105, no. 11, pp. 4179-4184, 2008.

[24] G. Eot-Houllier, G. Fulcrand, Y. Watanabe, L. MagnaghiJaulin, and C. Jaulin, "Histone deacetylase 3 is required for centromeric H3K4 deacetylation and sister chromatid cohesion," Genes and Development, vol. 22, no. 19, pp. 26392644, 2008.

[25] P. Gupta, P. C. Ho, S. G. Ha, Y. W. Lin, and L. N. Wei, "HDAC3 as a molecular chaperone for shuttling phosphorylated TR2 to PML: a novel deacetylase activity-independent function of HDAC3," PLoS One, vol. 4, no. 2, Article ID e4363, 2009.

[26] M. G. Guenther, J. Yu, G. D. Kao, T. J. Yen, and M. A. Lazar, "Assembly of the SMRT-histone deacetylase 3 repression complex requires the TCP-1 ring complex," Genes and Development, vol. 16, no. 24, pp. 3130-3135, 2002.

[27] M. Parra and E. Verdin, "Regulatory signal transduction pathways for class IIa histone deacetylases," Current Opinion in Pharmacology, vol. 10, no. 4, pp. 454-460, 2010.
[28] X. J. Yang and E. Seto, "The Rpd3/Hda1 family of lysine deacetylases: from bacteria and yeast to mice and men," Nature Reviews Molecular Cell Biology, vol. 9, no. 3, pp. 206218, 2008.

[29] V. Basile, R. Mantovani, and C. Imbriano, "DNA damage promotes histone deacetylase 4 nuclear localization and repression of G/M promoters, via p53 C-terminal lysines," Journal of Biological Chemistry, vol. 281, no. 4, pp. 23472357, 2006.

[30] E. J. Jeon, K. Y. Lee, N. S. Choi et al., "Bone morphogenetic protein-2 stimulates Runx2 acetylation," Journal of Biological Chemistry, vol. 281, no. 24, pp. 16502-16511, 2006.

[31] H. Y. Kao, A. Verdel, C. C. Tsai, C. Simon, H. Juguilon, and S. Khochbin, "Mechanism for nucleocytoplasmic shuttling of histone deacetylase 7," Journal of Biological Chemistry, vol. 276, no. 50, pp. 47496-47507, 2001.

[32] M. P. Gupta, S. A. Samant, S. H. Smith, and S. G. Shroff, "HDAC4 and PCAF bind to cardiac sarcomeres and play a role in regulating myofilament contractile activity," Journal of Biological Chemistry, vol. 283, no. 15, pp. 10135-10146, 2008.

[33] B. Chen and C. L. Cepko, "HDAC4 regulates neuronal survival in normal and diseased retinas," Science, vol. 323, no. 5911, pp. 256-259, 2009.

[34] J. W. Jeong, M. K. Bae, M. Y. Ahn et al., "Regulation and destabilization of HIF- $1 \alpha$ by ARD1-mediated acetylation," Cell, vol. 111, no. 5, pp. 709-720, 2002.

[35] J. Hageman, M. A. Rujano, M. A. W. H. van Waarde et al., "A DNAJB chaperone subfamily with HDAC-dependent activities suppresses toxic protein aggregation," Molecular Cell, vol. 37, no. 3, pp. 355-369, 2010.

[36] D. Bridges and G. B. Moorhead, "14-3-3 proteins: a number of functions for a numbered protein," Science's STKE, vol. 2005, no. 296, p. re10, 2005.

[37] T. G. Nishino, M. Miyazaki, H. Hoshino, Y. Miwa, S. Horinouchi, and M. Yoshida, "14-3-3 regulates the nuclear import of class IIa histone deacetylases," Biochemical and Biophysical Research Communications, vol. 377, no. 3, pp. 852-856, 2008.

[38] G. Paroni, N. Cernotta, C. D. Russo et al., "PP2A regulates HDAC4 nuclear import," Molecular Biology of the Cell, vol. 19, no. 2, pp. 655-667, 2008.

[39] S. Borghi, S. Molinari, G. Razzini, R. Parise, R. Battini, and S. Ferrari, "The nuclear localization domain of the MEF2 family of transcription factors shows member-specific features and mediates the nuclear import of histone deacetylase 4," Journal of Cell Science, vol. 114, no. 24, pp. 4477-4483, 2001.

[40] T. Ago, T. Liu, P. Zhai et al., "A redox-dependent pathway for regulating class II HDACs and cardiac hypertrophy," Cell, vol. 133, no. 6, pp. 978-993, 2008.

[41] F. Liu, M. Dowling, X. J. Yang, and G. D. Kao, "Caspasemediated specific cleavage of human histone deacetylase 4," Journal of Biological Chemistry, vol. 279, no. 33, pp. 3453734546, 2004.

[42] G. Paroni, M. Mizzau, C. Henderson, G. Del Sal, C. Schneider, and C. Brancolini, "Caspase-dependent regulation of histone deacetylase 4 nuclear-cytoplasmic shuttling promotes apoptosis," Molecular Biology of the Cell, vol. 15, no. 6, pp. 2804-2818, 2004.

[43] H. Kato, S. Tamamizu-Kato, and F. Shibasaki, "Histone deacetylase 7 associates with hypoxia-inducible factor $1 \alpha$ and increases transcriptional activity," Journal of Biological Chemistry, vol. 279, no. 40, pp. 41966-41974, 2004. 
[44] C. Gao, X. Cheng, M. Lam et al., "Signal-dependent regulation of transcription by histone deacetylase 7 involves recruitment to promyelocytic leukemia protein nuclear bodies," Molecular Biology of the Cell, vol. 19, no. 7, pp. 3020 3024, 2008.

[45] U. Karvonen, O. A. Jänne, and J. J. Palvimo, "Androgen receptor regulates nuclear trafficking and nuclear domain residency of corepressor HDAC7 in a ligand-dependent fashion," Experimental Cell Research, vol. 312, no. 16, pp. 3165-3183, 2006.

[46] O. Kirsh, J. S. Seeler, A. Pichler et al., "The SUMO E3 ligase RanBP2 promotes modification of the HDAC4 deacetylase," EMBO Journal, vol. 21, no. 11, pp. 2682-2691, 2002.

[47] S. Grégoire and X. J. Yang, "Association with class IIa histone deacetylases upregulates the sumoylation of MEF2 transcription factors," Molecular and Cellular Biology, vol. 25, no. 6, pp. 2273-2287, 2005.

[48] X. Zhao, T. Sternsdorf, T. A. Bolger, R. M. Evans, and T. P. Yao, "Regulation of MEF2 by histone beacetylase 4- and SIRT1 deacetylase-mediated lysine modifications," Molecular and Cellular Biology, vol. 25, no. 19, pp. 8456-8464, 2005.

[49] S. Jambunathan and J. D. Fontes, "Sumoylation of the zinc finger protein ZXDC enhances the function of its transcriptional activation domain," Biological Chemistry, vol. 388, no. 9, pp. 965-972, 2007.

[50] S. Ghisletti, W. Huang, S. Ogawa et al., "Parallel SUMOylation-dependent pathways mediate gene- and signal-specific transrepression by LXRs and PPARgamma," Molecular Cell, vol. 25, no. 1, pp. 57-70, 2007.

[51] J. H. Lee, S. M. Park, O. S. Kim et al., "Differential SUMOylation of LXRalpha and LXRbeta mediates transrepression of STAT1 inflammatory signaling in IFN-gamma-stimulated brain astrocytes," Molecular Cell, vol. 35, no. 6, pp. 806-817, 2009.

[52] E. D. Jensen, T. M. Schroeder, J. Bailey, R. Gopalakrishnan, and J. J. Westendorf, "Histone deacetylase 7 associates with Runx2 and represses its activity during osteoblast maturation in a deacetylation-independent manner," Journal of Bone and Mineral Research, vol. 23, no. 3, pp. 361-372, 2008.

[53] C. Gao, C. C. Ho, E. Reineke et al., "Histone deacetylase 7 promotes PML sumoylation and is essential for PML nuclear body formation," Molecular and Cellular Biology, vol. 28, no. 18, pp. 5658-5667, 2008.

[54] S. Aoyagi and T. K. Archer, "Modulating molecular chaperone Hsp90 functions through reversible acetylation," Trends in Cell Biology, vol. 15, no. 11, pp. 565-567, 2005.

[55] C. Boyault, K. Sadoul, M. Pabion, and S. Khochbin, "HDAC6, at the crossroads between cytoskeleton and cell signaling by acetylation and ubiquitination," Oncogene, vol. 26, no. 37, pp. 5468-5476, 2007.

[56] G. W. G. Luxton and G. G. Gundersen, "HDAC6-pack: cortactin acetylation joins the brew," Developmental Cell, vol. 13, no. 2, pp. 161-162, 2007.

[57] P. Matthias, M. Yoshida, and S. Khochbin, "HDAC6 a new cellular stress surveillance factor," Cell Cycle, vol. 7, no. 1, pp. 7-10, 2008.

[58] A. Valenzuela-Fernández, J. R. Cabrero, J. M. Serrador, and F. Sánchez-Madrid, "HDAC6: a key regulator of cytoskeleton, cell migration and cell-cell interactions," Trends in Cell Biology, vol. 18, no. 6, pp. 291-297, 2008.

[59] N. Tokési, A. Lehotzky, I. Horváth et al., “TPPP/p25 promotes tubulin acetylation by inhibiting histone deacetylase 6," Journal of Biological Chemistry, vol. 285, no. 23, pp. 17896-17906, 2010.
[60] S. A. Wickström, K. C. Masoumi, S. Khochbin, R. Fässler, and R. Massoumi, "CYLD negatively regulates cell-cycle progression by inactivating HDAC6 and increasing the levels of acetylated tubulin," The EMBO Journal, vol. 29, no. 1, pp. 131-144, 2010.

[61] Y. Wu, S. W. Song, J. Sun, J. M. Bruner, G. N. Fuller, and W. Zhang, "IIp45 inhibits cell migration through inhibition of HDAC6," Journal of Biological Chemistry, vol. 285, no. 6, pp. 3554-3560, 2010.

[62] M. Perez, I. Santa-Maria, E. G. De Barreda et al., "Tauan inhibitor of deacetylase HDAC6 function," Journal of Neurochemistry, vol. 109, no. 6, pp. 1756-1766, 2009.

[63] Y. L. Deribe, P. Wild, A. Chandrashaker et al., "Regulation of epidermal growth factor receptor trafficking by lysine deacetylase hdac6," Science Signaling, vol. 2, no. 102, p. ra84, 2009.

[64] B. T. Scroggins, K. Robzyk, D. Wang et al., "An acetylation site in the middle domain of Hsp90 regulates chaperone function," Molecular Cell, vol. 25, no. 1, pp. 151-159, 2007.

[65] J. J. Kovacs, P. J. M. Murphy, S. Gaillard et al., "HDAC6 regulates Hsp90 acetylation and chaperone-dependent activation of glucocorticoid receptor," Molecular Cell, vol. 18, no. 5, pp. 601-607, 2005.

[66] V. D. Kekatpure, A. J. Dannenberg, and K. Subbaramaiah, "HDAC6 modulates Hsp90 chaperone activity and regulates activation of aryl hydrocarbon receptor signaling," Journal of Biological Chemistry, vol. 284, no. 12, pp. 7436-7445, 2009.

[67] X. Zhang, Z. Yuan, Y. Zhang et al., "HDAC6 modulates cell motility by altering the acetylation level of cortactin," Molecular Cell, vol. 27, no. 2, pp. 197-213, 2007.

[68] J. Y. Lee, H. Koga, Y. Kawaguchi et al., "HDAC6 controls autophagosome maturation essential for ubiquitin-selective quality-control autophagy," EMBO Journal, vol. 29, no. 5, pp. 969-980, 2010.

[69] J. Y. Lee and T. P. Yao, "Quality control autophagy: a joint effort of ubiquitin, protein deacetylase and actin cytoskeleton," Autophagy, vol. 6, no. 4, pp. 555-557, 2010.

[70] Y. Li, X. Zhang, R. D. Polakiewicz, T. P. Yao, and M. J. Comb, "HDAC6 is required for epidermal growth factor-induced $\beta$ catenin nuclear localization," Journal of Biological Chemistry, vol. 283, no. 19, pp. 12686-12690, 2008.

[71] S. Amit, A. Hatzubai, Y. Birman et al., "Axin-mediated CKI phosphorylation of $\beta$-catenin at Ser 45: a molecular switch for the Wnt pathway," Genes and Development, vol. 16, no. 9, pp. 1066-1076, 2002.

[72] P. J. Morin, A. B. Sparks, V. Korinek et al., "Activation of $\beta$-catenin-Tcf signaling in colon cancer by mutations in $\beta$ catenin or APC," Science, vol. 275, no. 5307, pp. 1787-1790, 1997.

[73] R. B. Parmigiani, W. S. Xu, G. Venta-Perez et al., "HDAC6 is a specific deacetylase of peroxiredoxins and is involved in redox regulation," Proceedings of the National Academy of Sciences of the United States of America, vol. 105, no. 28, pp. 9633-9638, 2008.

[74] I. L. Lai, T. P. Lin, YA. L. Yao, C. Y. Lin, M. J. Hsieh, and W. M. Yang, "Histone deacetylase 10 relieves repression on the melanogenic program by maintaining the deacetylation status of repressors," Journal of Biological Chemistry, vol. 285, no. 10, pp. 7187-7196, 2010.

[75] Y. Wang, S. Y. Wang, XU. H. Zhang et al., "FK228 inhibits Hsp90 chaperone function in K562 cells via hyperacetylation of Hsp70," Biochemical and Biophysical Research Communications, vol. 356, no. 4, pp. 998-1003, 2007. 
[76] M. C. Haigis and D. A. Sinclair, "Mammalian sirtuins: biological insights and disease relevance," Annual Review of Pathology, vol. 5, pp. 253-295, 2010.

[77] M. Gertz and C. Steegborn, "Function and regulation of the mitochondrial Sirtuin isoform Sirt5 in Mammalia," Biochimica et Biophysica Acta, vol. 1804, no. 8, pp. 1658-1665, 2010.

[78] J. Y. Huang, M. D. Hirschey, T. Shimazu, L. Ho, and E. Verdin, "Mitochondrial sirtuins," Biochimica et Biophysica Acta, vol. 1804, no. 8, pp. 1645-1651, 2010.

[79] C. Schlicker, M. Gertz, P. Papatheodorou, B. Kachholz, C. F. W. Becker, and C. Steegborn, "Substrates and regulation mechanisms for the human mitochondrial sirtuins Sirt3 and Sirt5," Journal of Molecular Biology, vol. 382, no. 3, pp. 790801, 2008.

[80] T. Finkel, C. X. Deng, and R. Mostoslavsky, "Recent progress in the biology and physiology of sirtuins," Nature, vol. 460, no. 7255, pp. 587-591, 2009.

[81] D. M. Taylor, M. M. Maxwell, R. Luthi-Carter, and A. G. Kazantsev, "Biological and potential therapeutic roles of sirtuin deacetylases," Cellular and Molecular Life Sciences, vol. 65, no. 24, pp. 4000-4018, 2008.

[82] T. Inoue, M. Hiratsuka, M. Osaki, and M. Oshimura, "The molecular biology of mammalian SIRT proteins: SIRT2 in cell cycle regulation," Cell Cycle, vol. 6, no. 9, pp. 1011-1018, 2007.

[83] M. Tanno, J. Sakamoto, T. Miura, K. Shimamoto, and Y. Horio, "Nucleocytoplasmic shuttling of the NAD-dependent histone deacetylase SIRT1," Journal of Biological Chemistry, vol. 282, no. 9, pp. 6823-6832, 2007.

[84] Q. Jin, T. Yan, X. Ge, C. Sun, X. Shi, and Q. Zhai, "Cytoplasmlocalized SIRT1 enhances apoptosis," Journal of Cellular Physiology, vol. 213, no. 1, pp. 89-97, 2007.

[85] J. Luo, A. Y. Nikolaev, S. I. Imai et al., "Negative control of p53 by Sir $2 \alpha$ promotes cell survival under stress," Cell, vol. 107, no. 2, pp. 137-148, 2001.

[86] H. Vaziri, S. K. Dessain, E. N. Eaton et al., "hSIR2(SIRT1) functions as an NAD-dependent p53 deacetylase," Cell, vol. 107, no. 2, pp. 149-159, 2001.

[87] S. Greiss, J. Hall, S. Ahmed, and A. Gartner, "C. elegans SIR2.1 translocation is linked to a proapoptotic pathway parallel to cep-1/p53 during DNA damage-induced apoptosis," Genes and Development, vol. 22, no. 20, pp. 2831-2842, 2008.

[88] B. J. North, B. L. Marshall, M. T. Borra, J. M. Denu, and E. Verdin, "The human Sir2 ortholog, SIRT2, is an NADdependent tubulin deacetylase," Molecular Cell, vol. 11, no. 2, pp. 437-444, 2003.

[89] B. J. North and E. Verdin, "Interphase nucleo-cytoplasmic shuttling and localization of SIRT2 during mitosis," PLoS One, vol. 2, no. 8, article e784, 2007.

[90] J. M. Wilson, V. Q. Le, C. Zimmerman, R. Marmorstein, and L. Pillus, "Nuclear export modulates the cytoplasmic Sir2 homologue Hst2," EMBO Reports, vol. 7, no. 12, pp. 12471251, 2006.

[91] C. Das, M. S. Lucia, K. C. Hansen, and J. K. Tyler, "CBP/p300mediated acetylation of histone $\mathrm{H} 3$ on lysine 56," Nature, vol. 459, no. 7243, pp. 113-117, 2009.

[92] Y. H. Jin, Y. J. Kim, D. W. Kim et al., "Sirt2 interacts with 14$3-3 \beta / \gamma$ and down-regulates the activity of p53," Biochemical and Biophysical Research Communications, vol. 368, no. 3, pp. 690-695, 2008.
[93] A. Vaquero, M. B. Scher, H. L. Dong et al., "SirT2 is a histone deacetylase with preference for histone H4 Lys 16 during mitosis," Genes and Development, vol. 20, no. 10, pp. 12561261, 2006.

[94] F. Wang and Q. Tong, "SIRT2 suppresses adipocyte differentiation by deacetylating FOXO1 and enhancing FOXO1's repressive interaction with PPARy," Molecular Biology of the Cell, vol. 20, no. 3, pp. 801-808, 2009.

[95] Y. Zhao, J. Yang, W. Liao et al., "Cytosolic FoxO1 is essential for the induction of autophagy and tumour suppressor activity," Nature Cell Biology, vol. 12, no. 7, pp. 665-675, 2010.

[96] J. C. Black, A. Mosley, T. Kitada, M. Washburn, and M. Carey, "The SIRT2 deacetylase regulates autoacetylation of p300," Molecular Cell, vol. 32, no. 3, pp. 449-455, 2008.

[97] B. J. North and E. Verdin, "Mitotic regulation of SIRT2 by cyclin-dependent kinase 1-dependent phosphorylation," Journal of Biological Chemistry, vol. 282, no. 27, pp. 1954619555, 2007.

[98] R. Pandithage, R. Lilischkis, K. Harting et al., "The regulation of SIRT2 function by cyclin-dependent kinases affects cell motility," Journal of Cell Biology, vol. 180, no. 5, pp. 915-929, 2008.

[99] S. C. Dryden, F. A. Nahhas, J. E. Nowak, A. S. Goustin, and M. A. Tainsky, "Role for human SIRT2 NAD-dependent deacetylase activity in control of mitotic exit in the cell cycle," Molecular and Cellular Biology, vol. 23, no. 9, pp. 3173-3185, 2003.

[100] Y. Han, Y. H. Jin, Y. J. Kim et al., "Acetylation of Sirt2 by p300 attenuates its deacetylase activity," Biochemical and Biophysical Research Communications, vol. 375, no. 4, pp. 576-580, 2008.

[101] N. S. Bael, M. J. Swanson, A. Vassilev, and B. H. Howard, "Human histone deacetylase SIRT2 interacts with the homeobox transcription factor HOXA10," Journal of Biochemistry, vol. 135, no. 6, pp. 695-700, 2004.

[102] C. M. Southwood, M. Peppi, S. Dryden, M. A. Tainsky, and A. Gow, "Microtubule deacetylases, SirT2 and HDAC6, in the nervous system," Neurochemical Research, vol. 32, no. 2, pp. 187-195, 2007.

[103] K. Harting and B. Knöll, "SIRT2-mediated protein deacetylation: an emerging key regulator in brain physiology and pathology," European Journal of Cell Biology, vol. 89, no. 23, pp. 262-269, 2010.

[104] M. Hiratsuka, T. Inoue, T. Toda et al., "Proteomics-based identification of differentially expressed genes in human gliomas: down-regulation of SIRT2 gene," Biochemical and Biophysical Research Communications, vol. 309, no. 3, pp. 558-566, 2003.

[105] T. Inoue, M. Hiratsuka, M. Osaki et al., "SIRT2, a tubulin deacetylase, acts to block the entry to chromosome condensation in response to mitotic stress," Oncogene, vol. 26, no. 7, pp. 945-957, 2007.

[106] T. Inoue, Y. Nakayama, H. Yamada et al., "SIRT2 downregulation confers resistance to microtubule inhibitors by prolonging chronic mitotic arrest," Cell Cycle, vol. 8, no. 8, pp. 1279-1291, 2009.

[107] M. T. Borra, F. J. O’Neill, M. D. Jackson et al., “Conserved enzymatic production and biological effect of O-acetyl-ADPribose by silent information regulator 2-like NAD-dependent deacetylases," Journal of Biological Chemistry, vol. 277, no. 15, pp. 12632-12641, 2002. 
[108] D. M. Scolnick and T. D. Halazonetis, "Chfr defines a mitotic stress checkpoint that delays entry into metaphase," Nature, vol. 406, no. 6794, pp. 430-435, 2000.

[109] D. B. Lombard, F. W. Alt, H. L. Cheng et al., "Mammalian Sir2 homolog SIRT3 regulates global mitochondrial lysine acetylation," Molecular and Cellular Biology, vol. 27, no. 24, pp. 8807-8814, 2007.

[110] P. Onyango, I. Celic, J. M. McCaffery, J. D. Boeke, and A. P. Feinberg, "SIRT3, a human SIR2 homologue, is an NAD-dependent deacetylase localized to mitochondria," Proceedings of the National Academy of Sciences of the United States of America, vol. 99, no. 21, pp. 13653-13658, 2002.

[111] B. Schwer, J. Bunkenborg, R. O. Verdin, J. S. Andersen, and E. Verdin, "Reversible lysine acetylation controls the activity of the mitochondrial enzyme acetyl-CoA synthetase 2," Proceedings of the National Academy of Sciences of the United States of America, vol. 103, no. 27, pp. 10224-10229, 2006.

[112] L. Jin, W. Wei, Y. Jiang et al., "Crystal structures of human SIRT3 displaying substrate-induced conformational changes," Journal of Biological Chemistry, vol. 284, no. 36, pp. 24394-24405, 2009.

[113] Y. Nakamura, M. Ogura, D. Tanaka, and N. Inagaki, "Localization of mouse mitochondrial SIRT proteins: shift of SIRT3 to nucleus by co-expression with SIRT5," Biochemical and Biophysical Research Communications, vol. 366, no. 1, pp. 174-179, 2008.

[114] M. B. Scher, A. Vaquero, and D. Reinberg, "SirT3 is a nuclear NAD-dependent histone deacetylase that translocates to the mitochondria upon cellular stress," Genes and Development, vol. 21, no. 8, pp. 920-928, 2007.

[115] N. R. Sundaresan, S. A. Samant, V. B. Pillai, S. B. Rajamohan, and M. P. Gupta, "SIRT3 is a stress-responsive deacetylase in cardiomyocytes that protects cells from stress-mediated cell death by deacetylation of Ku70," Molecular and Cellular Biology, vol. 28, no. 20, pp. 6384-6401, 2008.

[116] W. C. Hallows, B. N. Albaugh, and J. M. Denu, "Where in the cell is SIRT3?-functional localization of an NAD+dependent protein deacetylase," The Biochemical Journal, vol. 411, no. 2, pp. e11-e13, 2008.

[117] H. M. Cooper, J.-Y. Huang, E. Verdin, and J. N. Spelbrink, "A new splice variant of the mouse SITR3 gene encodes the mithochondrial precursor protein," PLoS One, vol. 4, no. 3, article e4986, 2009.

[118] L. Jin, H. Galonek, K. Israelian et al., "Biochemical characterization, localization, and tissue distribution of the longer form of mouse SIRT3," Protein Science, vol. 18, no. 3, pp. 514$525,2009$.

[119] T. Shi, F. Wang, E. Stieren, and Q. Tong, "SIRT3, a mitochondrial sirtuin deacetylase, regulates mitochondrial function and thermogenesis in brown adipocytes," Journal of Biological Chemistry, vol. 280, no. 14, pp. 13560-13567, 2005.

[120] Y. H. Yang, Y. H. Chen, C. Y. Zhang, M. A. Nimmakayalu, D. C. Ward, and S. Weissman, "Cloning and characterization of two mouse genes with homology to the yeast Sir2 gene," Genomics, vol. 69, no. 3, pp. 355-369, 2000.

[121] W. C. Hallows, S. Lee, and J. M. Denu, "Sirtuins deacetylate and activate mammalian acetyl-CoA synthetases," Proceedings of the National Academy of Sciences of the United States of America, vol. 103, no. 27, pp. 10230-10235, 2006.

[122] B. H. Ahn, H. S. Kim, S. Song et al., "A role for the mitochondrial deacetylase Sirt3 in regulating energy homeostasis," Proceedings of the National Academy of Sciences of the United States of America, vol. 105, no. 38, pp. 14447-14452, 2008.
[123] H. Yang, T. Yang, J. A. Baur et al., "Nutrient-sensitive mitochondrial NAD+ levels dictate cell survival," Cell, vol. 130, no. 6, pp. 1095-1107, 2007.

[124] Y. Yang, H. Cimen, M. J. Han et al., "NAD-dependent deacetylase SIRT3 regulates mitochondrial protein synthesis by deacetylation of the ribosomal protein MRPL10," Journal of Biological Chemistry, vol. 285, no. 10, pp. 7417-7429, 2010.

[125] T. Fujino, J. Kondo, M. Ishikawa, K. Morikawa, and T. T. Yamamoto, "Acetyl-CoA synthetase 2, a mitochondrial matrix enzyme involved in the oxidation of acetate," Journal of Biological Chemistry, vol. 276, no. 14, pp. 11420-11426, 2001.

[126] C. A. Stanley, "Hyperinsulinism/hyperammonemia syndrome: insights into the regulatory role of glutamate dehydrogenase in ammonia metabolism," Molecular Genetics and Metabolism, vol. 81, supplement 1, pp. S45-S51, 2004.

[127] T. Nakagawa, D. J. Lomb, M. C. Haigis, and L. Guarente, "SIRT5 deacetylates carbamoyl phosphate synthetase 1 and regulates the urea cycle," Cell, vol. 137, no. 3, pp. 560-570, 2009.

[128] R. M. Anderson, K. J. Bitterman, J. G. Wood, O. Medvedik, and D. A. Sinclair, "Nicatinamide and PNC1 govern lifespan extension by calorie restriction in Saccharomyces cerevisiae," Nature, vol. 423, no. 6936, pp. 181-185, 2003.

[129] C. M. Gallo, D. L. Smith, and J. S. Smith, "Nicotinamide clearance by Pnc1 directly regulates Sir2-mediated silencing and longevity," Molecular and Cellular Biology, vol. 24, no. 3, pp. 1301-1312, 2004.

[130] A. Benigni, D. Corna, C. Zoja et al., "Disruption of the Ang II type 1 receptor promotes longevity in mice," Journal of Clinical Investigation, vol. 119, no. 3, pp. 524-530, 2009.

[131] S. J. Allison and JO. Milner, "SIRT3 is pro-apoptotic and participates in distinct basal apoptotic pathways," Cell Cycle, vol. 6, no. 21, pp. 2669-2677, 2007.

[132] N. Ahuja, B. Schwer, S. Carobbio et al., "Regulation of insulin secretion by SIRT4, a mitochondrial ADPribosyltransferase," Journal of Biological Chemistry, vol. 282, no. 46, pp. 33583-33592, 2007.

[133] M. C. Haigis, R. Mostoslavsky, K. M. Haigis et al., "SIRT4 inhibits glutamate dehydrogenase and opposes the effects of calorie restriction in pancreatic beta cells," Cell, vol. 126, no. 5, pp. 941-954, 2006.

[134] E. Michishita, J. Y. Park, J. M. Burneskis, J. C. Barrett, and I. Horikawa, "Evolutionarily conserved and nonconserved cellular localizations and functions of human SIRT proteins," Molecular Biology of the Cell, vol. 16, no. 10, pp. 4623-4635, 2005.

[135] P. Maechler, "Novel regulation of insulin secretion: the role of mitochondria," Current Opinion in Investigational Drugs, vol. 4, no. 10, pp. 1166-1172, 2003.

[136] K. Hagopian, J. J. Ramsey, and R. Weindruch, "Caloric restriction increases gluconeogenic and transaminase enzyme activities in mouse liver," Experimental Gerontology, vol. 38, no. 3, pp. 267-278, 2003.

[137] J. M. Dhahbi, P. L. Mote, J. Wingo et al., "Caloric restriction alters the feeding response of key metabolic enzyme genes," Mechanisms of Ageing and Development, vol. 122, no. 10, pp. 1033-1048, 2001.

[138] E. Michishita, J. Y. Park, J. M. Burneskis, J. C. Barrett, and I. Horikawa, "Evolutionarily conserved and nonconserved cellular localizations and functions of human SIRT proteins," Molecular Biology of the Cell, vol. 16, no. 10, pp. 4623-4635, 2005. 
[139] J. A. Pfister, C. Ma, B. E. Morrison, and S. R. D’Mello, "Opposing effects of sirtuins on neuronal survival: SIRT1mediated neuroprotection is independent of its deacetylase activity," PLoS One, vol. 3, no. 12, Article ID e4090, 2008.

[140] D. Haussinger, "Nitrogen metabolism in liver: structural and functional organization and physiological relevance," Biochemical Journal, vol. 267, no. 2, pp. 281-290, 1990.

[141] A. J. Meijer, W. H. Lamers, and R. A. F. M. Chamuleau, "Nitrogen metabolism and ornithine cycle function," Physiological Reviews, vol. 70, no. 3, pp. 701-748, 1990.

[142] S. M. Morris, "Regulation of enzymes of the urea cycle and arginine metabolism," Annual Review of Nutrition, vol. 22, pp. 87-105, 2002.

[143] R. T. Schimke, "Adaptive characteristics of urea cycle enzymes in the rat," Journal of Biological Chemistry, vol. 237, pp. 459468, 1962.

[144] R. T. Schimke, "Differential effects of fasting and protein-free diets on levels of urea cycle enzymes in rat liver," Journal of Biological Chemistry, vol. 237, pp. 1921-1924, 1962.

[145] B. Schwer, M. Eckersdorff, Y. Li et al., "Calorie restriction alters mitochondrial protein acetylation," Aging Cell, vol. 8, no. 5, pp. 604-606, 2009.

[146] C. S. Lieber, "Metabolism of alcohol," Clinics in Liver Disease, vol. 9, no. 1, pp. 1-35, 2005.

[147] C. S. Lieber, M. A. Leo, X. Wang, and L. M. DeCarli, "Alcohol alters hepatic FoxO1, p53, and mitochondrial SIRT5 deacetylation function," Biochemical and Biophysical Research Communications, vol. 373, no. 2, pp. 246-252, 2008. 

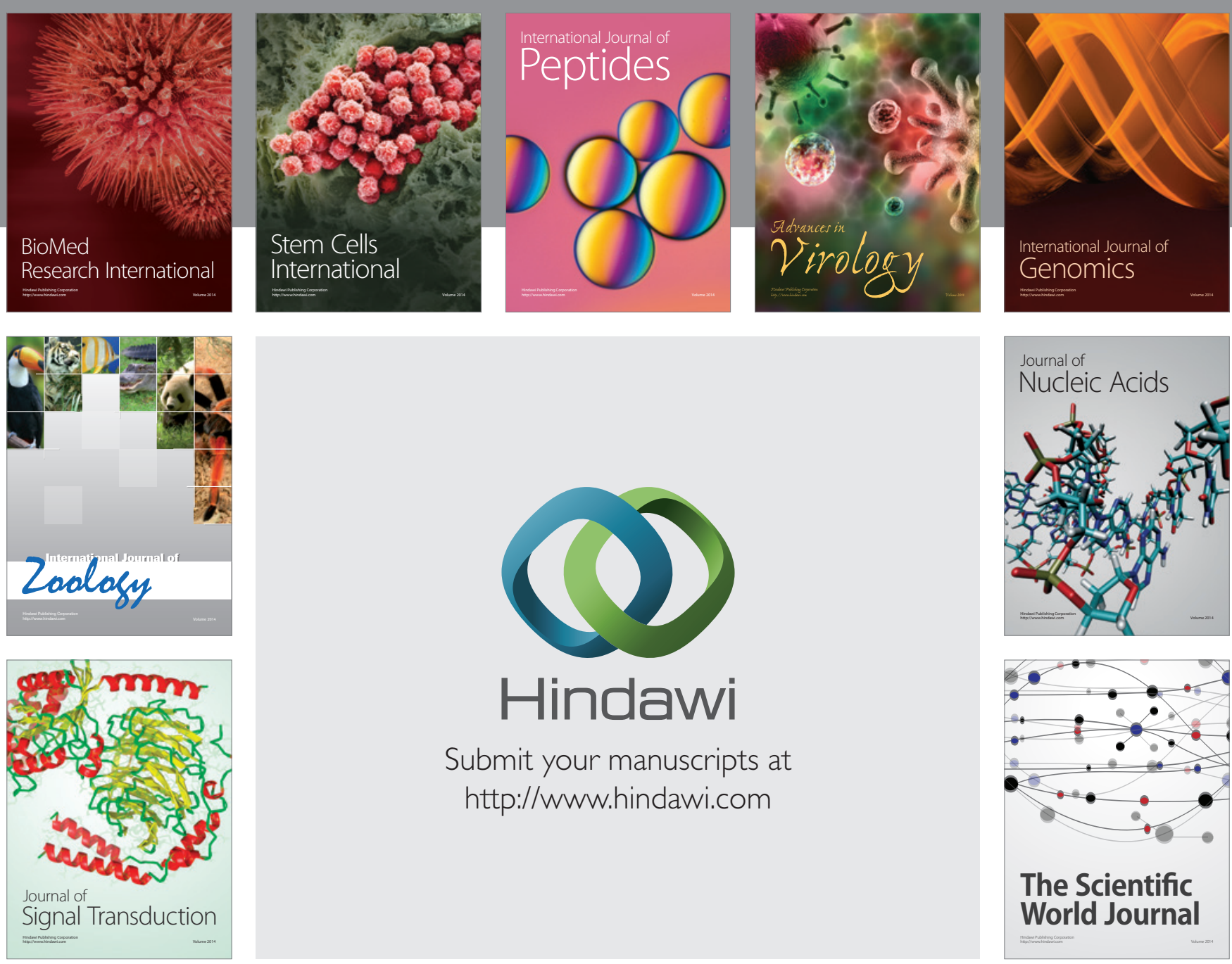

Submit your manuscripts at

http://www.hindawi.com
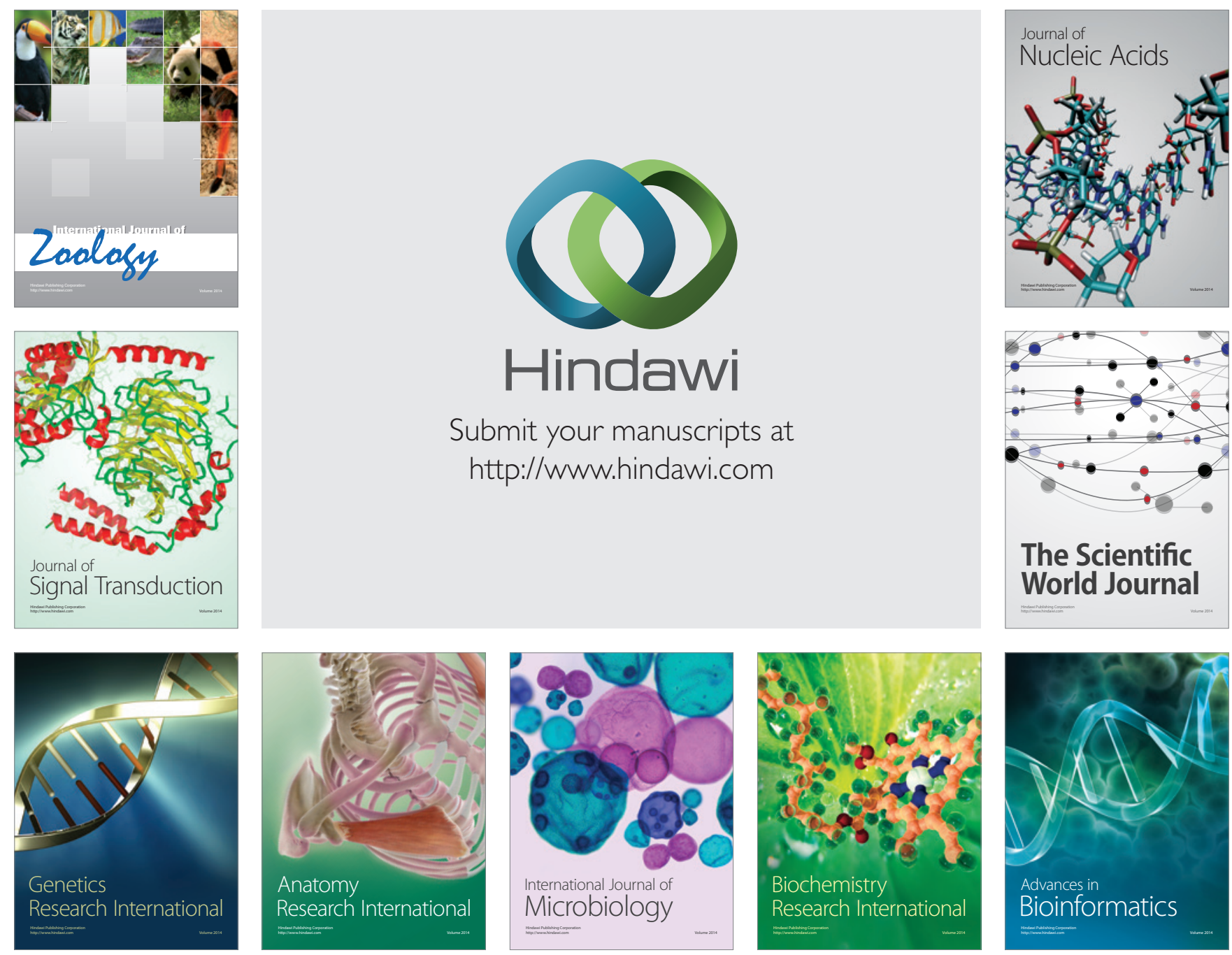

The Scientific World Journal
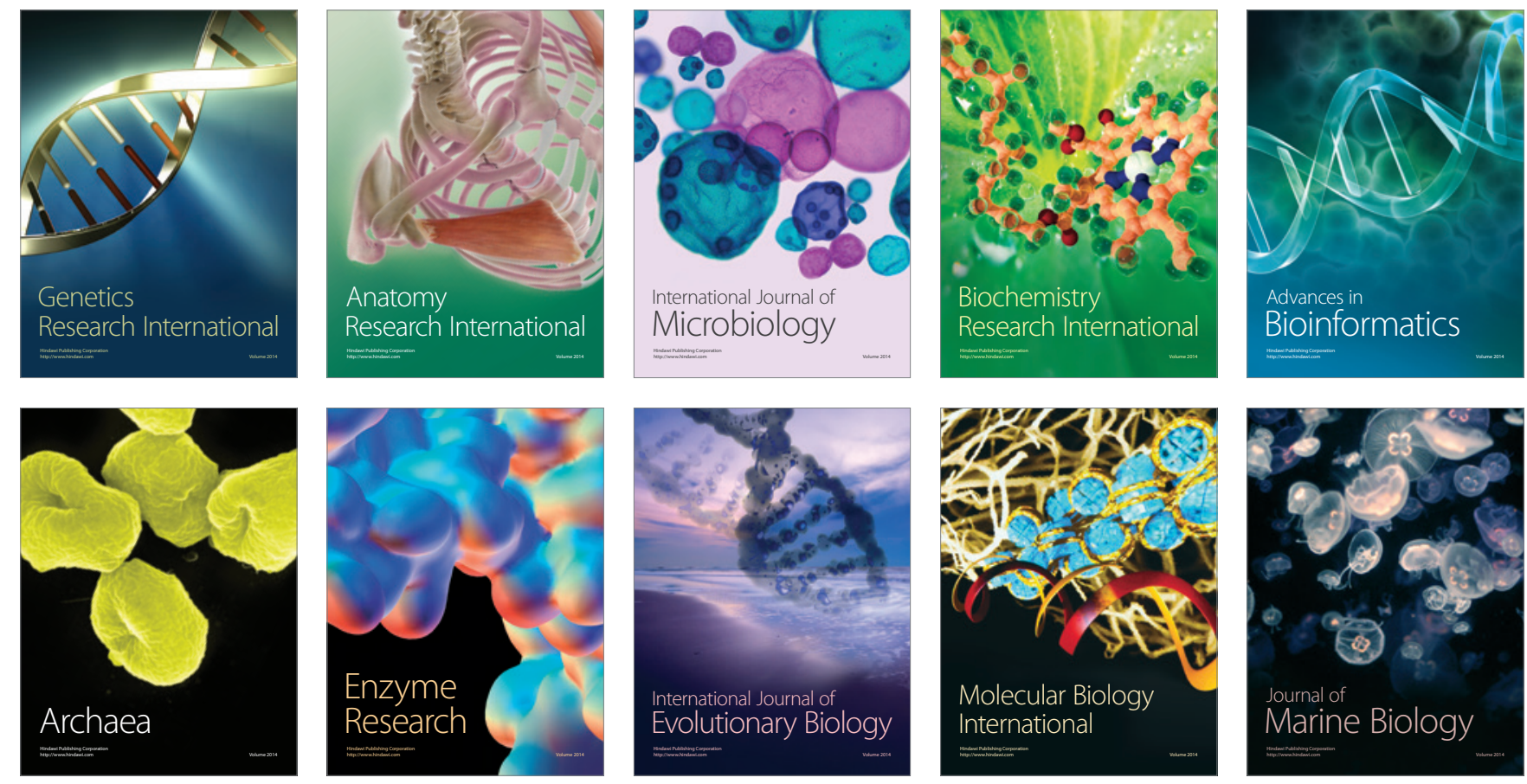